\title{
Supramolecular gels: Functions and uses
}

\author{
Neralagatta M. Sangeetha and Uday Maitra*
}

Received 28th June 2005

First published as an Advance Article on the web 23rd August 2005

DOI: $10.1039 / b 417081 b$

In recent years there has been immense interest in studying gels derived from low molecular mass gelators (supramolecular, or simply molecular gels). The motivation for this is not only to understand the fundamental aggregate structures in the gels at different length scales, but also to explore their potential for futuristic technological applications. Gels have been made sensitive to external stimuli like light and chemical entities by incorporating a spectroscopically active or a receptor unit as part of the gelator molecule. This makes them suitable for applications such as sensing and actuating. The diversity of gel structural architectures has allowed them to be utilized as templates to prepare novel inorganic superstructures for possible applications in catalysis and separation. Gels derived from liquid crystals (anisotropy gels) that can act as dynamically functional materials have been prepared, for example, for (re-writable) information recording. Supramolecular gels can be important in controlled release applications, in oil recovery, for gelling cryogenic fuels etc. They can also serve as media for a range of applications. This tutorial review highlights some of the instructive work done by various groups to develop smart and functional gels, and covers a wide spectrum of scientific interest ranging from medicine to materials science.

\section{Introduction}

Gels have pervaded our everyday life in a variety of forms. The wet soft solids that we encounter in the form of commercial products such as soap, shampoo, toothpaste, hair gel and other cosmetics, as well as contact lenses and gel pens etc. are all gels derived from polymeric compounds. Polymer gels have been known for centuries and applications in fields as diverse as food, medicine, materials science, cosmetics, pharmacology,

Department of Organic Chemistry, Indian Institute of Science, Bangalore 560 012, India sanitation etc. have been realized for these systems. ${ }^{1}$ Gels derived from low molecular mass compounds ("physical gels", or "supramolecular gels"), although known for a long time, have started to be actively investigated only during the past fifteen years, and applications as diverse as those realized for their polymeric counterparts have been envisaged for these systems. ${ }^{2}$ In general, gels are viscoelastic solid-like materials comprised of an elastic cross-linked network and a solvent, which is the major component. The solid-like appearance of a gel is a result of the entrapment and adhesion of the liquid in the large surface area solid 3D matrix. The formation of the solid matrix is a result of cross-linking of

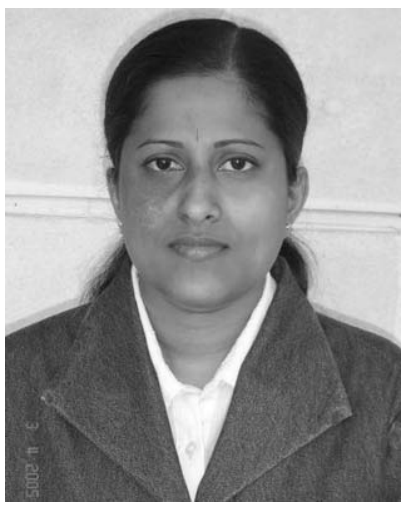

Neralagatta Sangeetha
Neralagatta Sangeetha was born in 1974 at Bangalore, India. She received her masters degree from the Bangalore University in 1997. In the same year she joined the Department of organic chemistry, at the Indian Institute of Science, Bangalore, India to pursue research towards her PhD degree under the guidance of Prof. Uday Maitra. She worked at CEA, Grenoble, France in the laboratory of $\mathrm{Dr}$ Pierre Terech in the summer of 2002 where she carried out rheological characterizations of supramolecular gels. She defended her thesis entitled 'Studies on physical gels derived from low molecular mass gelators' in August 2003 and moved on to CEA, Grenoble for a postdoctoral tenure in the same lab. Currently she is a postdoctoral fellow in the group of

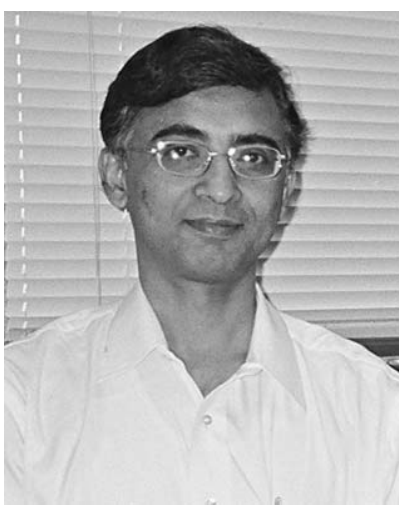

Uday Maitra
Prof. Jean-Pierre Desvergne at Laboratoire de chimie organique et organométallique, Université Bordeaux 1, France.

Uday Maitra had his early education at Presidency College, Calcutta and at IIT Kanpur. He did his PhD work at Columbia University with Prof. Ronald Breslow, followed by postdoctoral work at the University of California, Berkeley, with Prof. Paul A. Bartlett. He has been at the Indian Institute of Science, Bangalore since 1989 where he is currently a full Professor. His research interests include supramolecular chemistry, bile acid chemistry, and chemistry and physics of gels. He is also greatly interested in chemical education. 
the polymeric strands of (macro) molecules by physical or chemical forces.

Gels can be classified in different ways depending upon their origin, constitution, the type of cross-linking that creates their $3 \mathrm{D}$ network and the medium they encompass (Fig. 1). ${ }^{1}$ Most of the naturally occurring gelators are macromolecular and they form gels by physical cross-linking (usually H-bonding). ${ }^{3}$ Such macromolecules include gelatin, collagen, agar, starch and gellan gum. Gels derived from synthetic compounds can be subdivided on the basis of their constitution into macromolecular (polymer) and molecular. The formation of gels from macromolecular compounds can either result from chemical cross-linking or physical interactions. When the gels are formed by strong chemical bonds, they cannot be redissolved and are thermally irreversible (e.g., polyester, polyamide, poly(vinyl alcohol), polyethylene) whereas gels formed by weak noncovalent interactions (physical entanglements) are reversible (e.g. polyacrylate, polymethacrylate). Gels derived from low molecular mass compounds are supramolecular in the strictest sense in that they are formed through self-aggregation of the small gelator molecules to form entangled Self-Assembled Fibrillar Networks (SAFINs) through a combination of non-covalent interactions like H-bonding, $\pi-\pi$ stacking, donor-acceptor interactions, metal coordination, solvophobic forces (hydrophobic forces for gels in water) and van der Waals interactions. Since these networks involve weak interactions, they can be readily transformed to a fluid (sol) by heating and are generally thermally reversible.

\subsection{Supramolecular gels}

Although a low molecular mass gelator was discovered in the early nineteenth century, ${ }^{4}$ the supramolecular nature of these materials was poorly understood and they were largely neglected until the late 20th century. In the recent past, molecules of a great structural diversity, for instance from the simplest alkanes to the complex phthalocyanines, have been discovered to be gelators. Chart 1 provides a list of representative gelator molecules. Incidentally, the discovery of such molecules has been largely serendipitous (typically from a failed crystallization attempt!). However, with the knowledge gained on the aggregation of gelator molecules during the past decade, attempts are being made to 'design' gelators through the incorporation of structural features (for

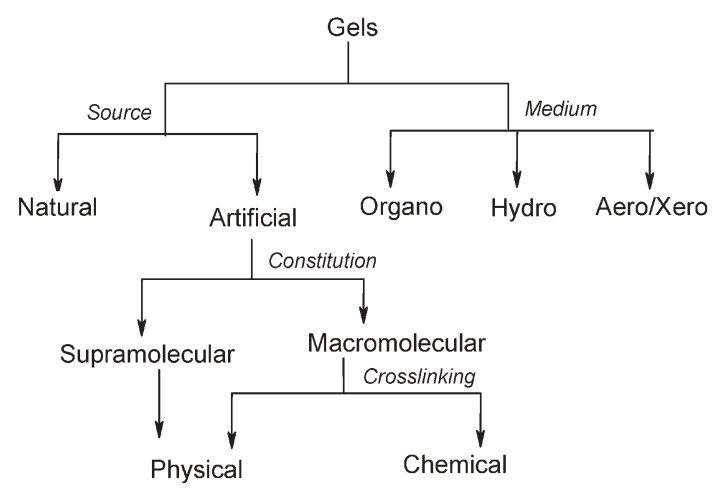

Fig. 1 Classification of gels. instance, H-bonding motifs such as amides, ureas and saccharides) ${ }^{5}$ that are known to promote one-dimensional aggregation.

Gels of a low molecular mass compound are usually prepared by heating the gelator in an appropriate solvent and cooling the resulting isotropic supersaturated solution to room temperature. When the hot solution is cooled, the molecules start to condense and three situations are possible (Fig. 2): (1) a highly ordered aggregation giving rise to crystals i.e., crystallization (2) a random aggregation resulting in an amorphous precipitate or (3) an aggregation process intermediate between these two, yielding a gel. The process of gelation involves self-association of the gelator molecules to form long, polymer-like fibrous aggregates, which get entangled during the aggregation process forming a matrix that traps the solvent mainly by surface tension. This process prevents the flow of solvent under gravity and the mass appears like a solid. Fig. 3 shows a typical Scanning Electron Micrograph of such a gel matrix formed by the self-assembly of an aqueous gelator. The matrix structure is heterogeneous and superstructures ranging in size from nanometers to micrometers can be found as a result of the hierarchal aggregation process. At the microscopic level, the structures and morphologies of supramolecular gels have been investigated by conventional imaging techniques such as SEM, TEM, and AFM, while thermal and mechanical studies are used to understand the interactions between these structures. $^{2 a}$ However, at the nanoscale, X-ray diffraction, small angle neutron scattering and X-ray scattering (SANS, SAXS) are required to elucidate the structures of supramolecular gels. In spite of all these investigations, several aspects of the process by which gelators aggregate to form gels are poorly understood and the process of gel formation remains an area of intense interest. ${ }^{2 a}$ However, despite the lack of a detailed understanding of the mode of aggregation of gelators, or the structures of the aggregates, a wide variety of futuristic applications have been envisioned for these materials. Several reviews and articles have described the diversity of the molecular structures of gelators and have attempted to shed light on the structure and properties of their supramolecular aggregates. $^{2}$ This review will describe the efforts to modify gels/gelators in order to develop a variety of functional gels which may have possible applications.

\section{Gels that respond to external stimuli: smart gels for sensing}

The intrinsic property of supramolecular gels to exhibit a reversible gel to sol phase transition in response to heat makes them amenable to thermosensing applications. Furthermore, supramolecular gels can be rendered sensitive to external stimuli such as light or chemicals by incorporating a receptor unit or a spectroscopically active (photoisomerizable) unit as part of the gelator molecule. For instance, the induction of light-sensitivity is usually achieved by incorporating azobenzene or anthracene units as photoisomerizable groups. Here, the gel-sol phase transition is readily triggered by light, which converts the gelator to an isomer which is a poorer gelator (and vice versa). Similarly, in gelators containing acidic or 


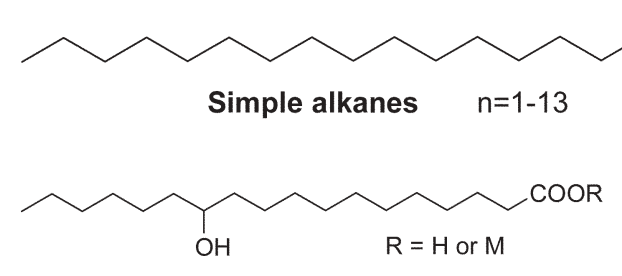

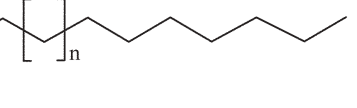

12-Hydroxystearic acid<smiles>CCCC1(CCC)CCC2C3CCC4CC(O)CCC4(C)C3CCC2(C)N1O</smiles><smiles>OCC(O)C1COCC2OCC(c3ccccc3)OC1O2</smiles>

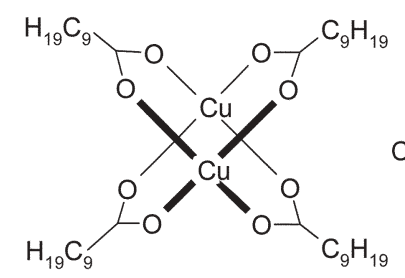

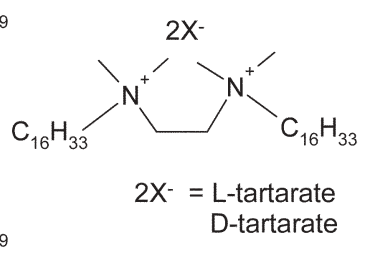<smiles>CCCCCCCCCCCCCCOC1=CC2C(=O)c3ccccc3C(=O)C2C=C1OCCCCCC</smiles>

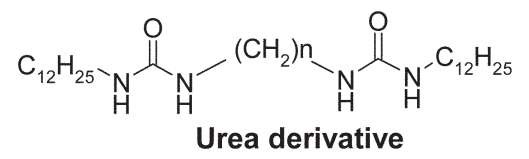<smiles>O=C1c2ccc([N+](=O)[O-])cc2-c2cc([N+](=O)[O-])cc([N+](=O)[O-])c21</smiles><smiles>[R]C(O)c1ccccc1CS(=O)(=O)[O-]</smiles>

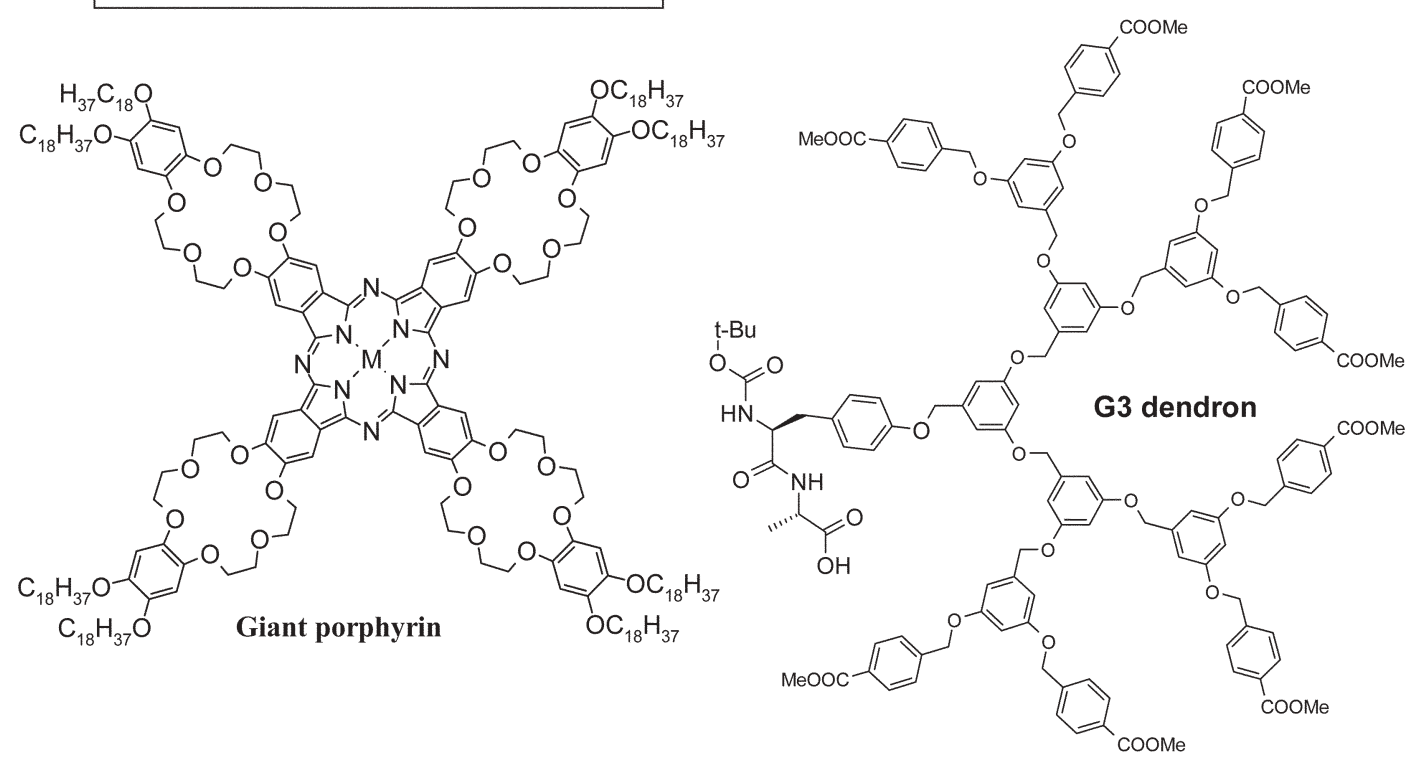

Chart 1 Structurally diverse molecular gelators.

basic groups, the gel-sol transition can be reversibly switched by appropriate changes in $\mathrm{pH}$. For gelators with receptor units, a molecular recognition event changes the supramolecular organization and alters the physical property of the gel. The need for an effective coupling between the recognition event and the self-organization event often dictates that the receptor unit must be an active component participating in the self-assembly process, as illustrated in some of the examples discussed below. Eventually, such recognition-driven supramolecular functional materials could be used to construct molecular devices such as sensors and actuators.

\subsection{Gelators with receptor sites or photoisomerizable groups}

Shinkai and coworkers have reported several examples of stimuli sensitive supramolecular gels. Most of these gelators are derived from naturally occurring cholesterol, with one or two cholesteryl units attached to a chromophore. In one of the earliest examples, an $n$-butanol gel of cholesterol derivatized with an azobenzyl group S1 (Chart 2) was shown to be photoresponsive. ${ }^{6}$ The sol-gel transition was induced reversibly by irradiating with lights of different wavelengths. The trans form aggregates readily to a gel, but the photoisomerized cis form 


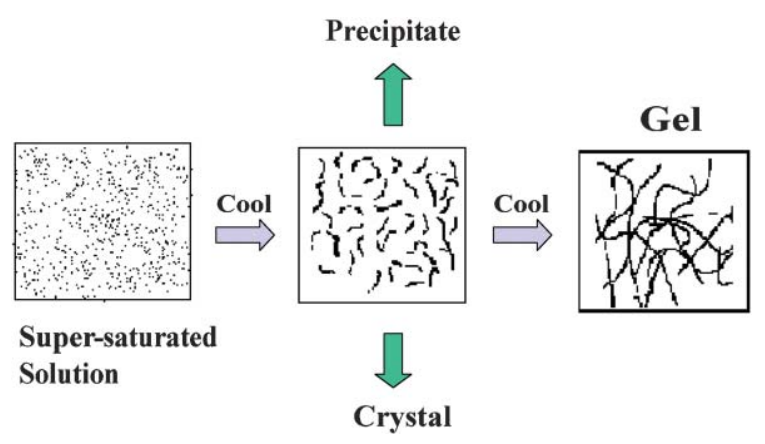

Fig. 2 Schematic representation of aggregation modes.

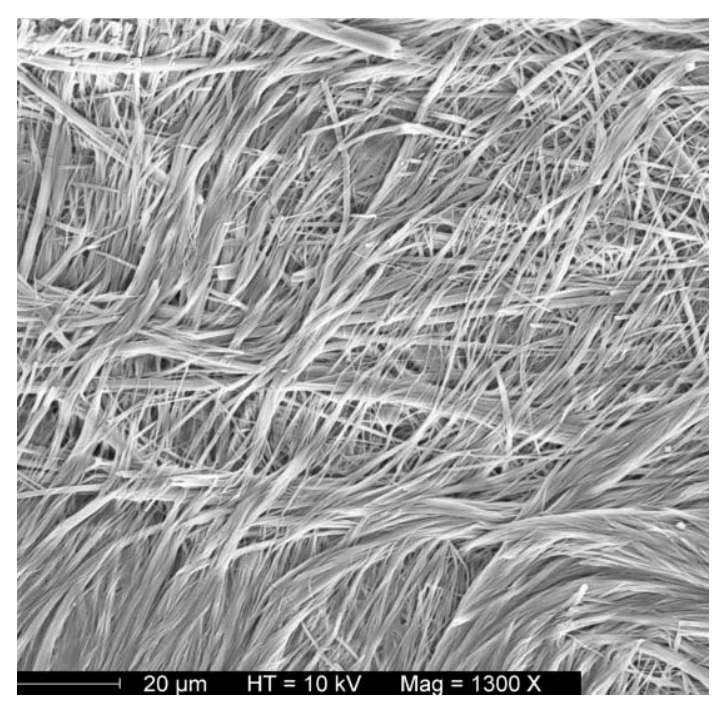

Fig. 3 SEM of an aqueous gel of a cationic bile acid derivative.

cannot form an extended molecular aggregation, and thus stays in solution. As a result, the irradiation of a butanol gel of S1 with UV-light (330-380 $\mathrm{nm}$ ) initiates a trans-cis isomerization of the azobenzyl moiety, and hence induces a gel to sol transition. The sol may be converted back to the gel by photoisomerizing the cis to the trans form by visible light (>460 nm).

Gel derived from an azacrown derivative of cholesterol S2 (Chart 2) in $4: 1$ methylcyclohexane/benzene responded to added alkali metal or ammonium ions. ${ }^{6}$ An increase in the concentration of various cations (such as $\mathrm{Li}^{+}, \mathrm{Na}^{+}, \mathrm{K}^{+}, \mathrm{Rb}^{+}$ and $\mathrm{NH}_{4}{ }^{+}$), which bind to the crown ether, caused an increase in the gel-sol transition temperature $\left(T_{\mathrm{g}}\right)$ of the gel. Interestingly, this increase was not continuous: a saturation point was reached and the $T_{\mathrm{g}}$ decreased gradually beyond this point. Notably, thermal gel stabilization was not possible in the presence of the larger cation $\mathrm{Cs}^{+}$, and only a gradual decrease in $T_{\mathrm{g}}$ was observed.

A gel of decylammonium salt of anthracene-9-carboxylate S3 (Chart 2) was shown to be both photochemically and thermally responsive. ${ }^{7}$ Upon irradiation with a mercury lamp, the gel in cyclohexane at $15{ }^{\circ} \mathrm{C}$ transformed into a sol via photo-induced dimerization of the anthracene units leading to a non-gelator. However, warming this sol to $30{ }^{\circ} \mathrm{C}$ in the dark thermally dissociates the anthracene dimer, and the gelator is<smiles>[R]OC(=O)c1ccc(N=Nc2ccc(OC)cc2)cc1</smiles>

S1<smiles>[R]OC(=O)COc1ccc(N=Nc2ccc(OCCOCC)c(OCCOCCOCC)c2)cc1</smiles><smiles>[R]O[C@H]1CC[C@@]2(C)C(=CCC3C2CC[C@]2(C)[C@H]3CC[C@@H]2[C@H](C)CCCC(C)C)C1</smiles>

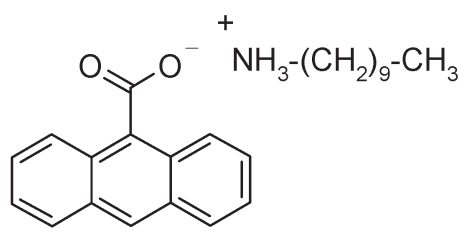

S3

Chart 2 Stimuli sensitive gels.

regenerated which leads to a precipitate. The initially formed precipitate may be heated to form a sol and subsequent cooling produces the gel.

Organogels of $2 \mathrm{H}$-chromene derivatives of sodium $\mathrm{N}$-acyl11-amino undecanoate ( $\mathbf{S 4}$ and S5; Chart 3) were shown to be both light and $\mathrm{pH}$ sensitive. ${ }^{8}$ The sodium salts of $\mathbf{S 4}$ and $\mathbf{S 5}$ formed gels in DMF and DMSO over a wide range of concentration. The neutral carboxylic acid forms were readily soluble in DMF and DMSO at ambient temperatures and formed gels when $\mathrm{NaOH}$ was added. Furthermore, when the gels were irradiated at $366 \mathrm{~nm}$, the gel rapidly developed a yellow color and started to flow upon inversion. Once the irradiation was stopped, the color faded, eventually yielding a colorless viscous solution. The original gel was readily regenerated from this sample by heating and then cooling the solution. These transitions were caused by the photoinduced ring opening of the colorless cyclic form to the colored acyclic form (shown in Chart 3), which partially disrupts the gel structure due to its incompatibility with the network. The acyclic form is, however, thermally unstable and returns to the cyclic one upon heating, yielding a sol which can be cooled to the gel.

In an interesting work, switching of the chirality of the supramolecular aggregates of a gel derived from a dithienylethene derivative $\mathbf{S 6}$ (Chart 4) has been realised using a similar interconversion between cyclic and acyclic forms with the aid of light. ${ }^{9}$ The gelator $\mathbf{S 6}$ exists in the acyclic form as $P$ - and $M$-helical conformers and undergoes reversible 
<smiles>[Y]c1ccc2c(c1)C=CC(=O)/C2=C\C=C(c1ccccc1)c1ccccc1</smiles><smiles>[Y][R]O[Na]</smiles>

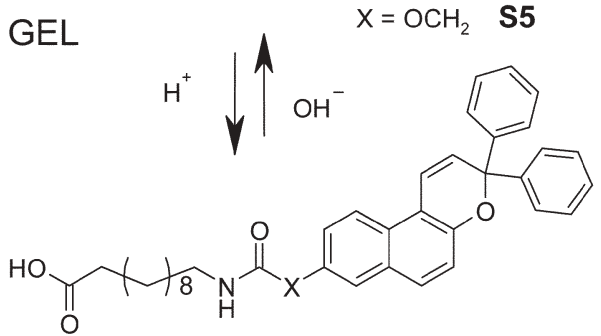

$\mathrm{SOL}$

Chart 3 2H-Chromene based gelator.

photocyclization to yield a diastereomeric pair of cyclic forms. Both forms could gelate toluene and when an isotropic solution of the acyclic form of $\mathbf{S 6}$ in toluene was cooled, a stable gel of $P$-helicity was obtained. Irradiating this gel at $313 \mathrm{~nm}$ resulted in a metastable gel ( $P$-helicity) of the cyclic form with a diastereoselectivity of $96 \%$. The high diastereoselectivity obtained has been attributed to the existence of only one of the acyclic conformers ( $P$-helical or $M$-helical) in the fibres due to stereoselective aggregation. When this metastable gel was heated to obtain an isotropic solution and cooled, it gave a thermodynamically stable gel of the cyclic form with $M$-helicity. Furthermore, irradiating this gel with visible light gave a metastable gel of the acyclic form with $M$-helicity, which upon a heating and cooling cycle returned to the original gel (acyclic form with $P$-helicity) (Chart 4). Thus, the supramolecular chirality was preserved during both photochemical reactions (ring-opening and ring-closing steps), yielding thermodynamically less favored aggregate structures (and hence metastable gels which could be obtained by only this route) and these could easily be converted to the thermodynamically favored aggregates via a heating and cooling cycle.

Bis-alkoxy derivatives of anthracene $\mathbf{S 7}$ (Chart 5) that gelled a variety of organic liquids such as alkanes, alcohols, aliphatic amines, and nitriles were modified by the introduction of basic nitrogen atoms, making the organogelation process $\mathrm{pH}$ sensitive. ${ }^{10}$ The modified derivative 2,3-dialkoxy phenazine $\mathbf{S 8}$ (Chart 5) gelled polar organic liquids like $\mathrm{EtOH}, \mathrm{MeOH}$, DMF and acetonitrile, and the gelation in acetonitrile could be fine-tuned by reversible protonation of the basic sites on the gelator. The thermal stability $\left(T_{\mathrm{g}}\right)$ increased till 1 equivalent of $\mathrm{H}^{+}$was added. A further increase in the concentration of acid had a deleterious effect on the gel, which caused a decrease in $T_{\mathrm{g}}$. However, the gel was found to recover its initial $T_{\mathrm{g}}$ if ammonia is bubbled through the system.

An organogelator containing a 1,10-phenanthroline unit with two cholesteryl arms $\mathbf{S 9}$ (Chart 5) gelled solvents such as alcohols, organic acids, DMF, DMSO, and $\mathrm{Et}_{3} \mathrm{~N}^{11}$ The gel prepared in 1-propanol showed interesting fluorescence behavior: the colorless translucent gel was purple under UV light, and turned greenish yellow upon the addition of TFA indicating that the gel is proton-sensitive. Heating this gel

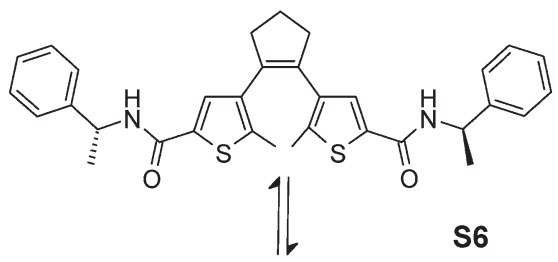<smiles>CC(NC(=O)C1=CC2=C3CCCC3=C3C=C(C(=O)N[C@@H](C)c4ccccc4)SC3(C)C2(C)S1)c1ccccc1</smiles>

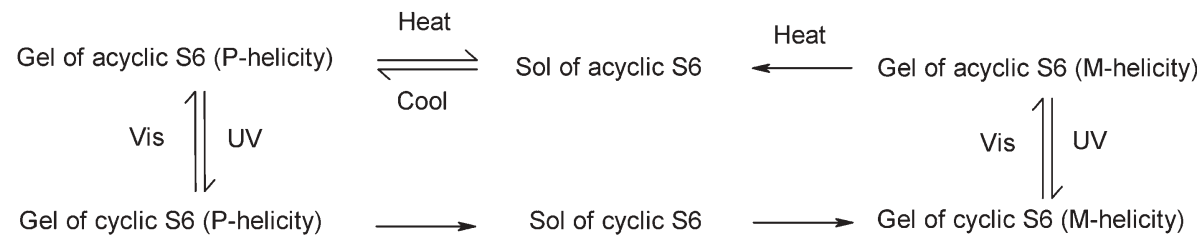

Chart 4 Dithienylethene based gelator and the schematic of the photo-switching of supramolecular chirality. 


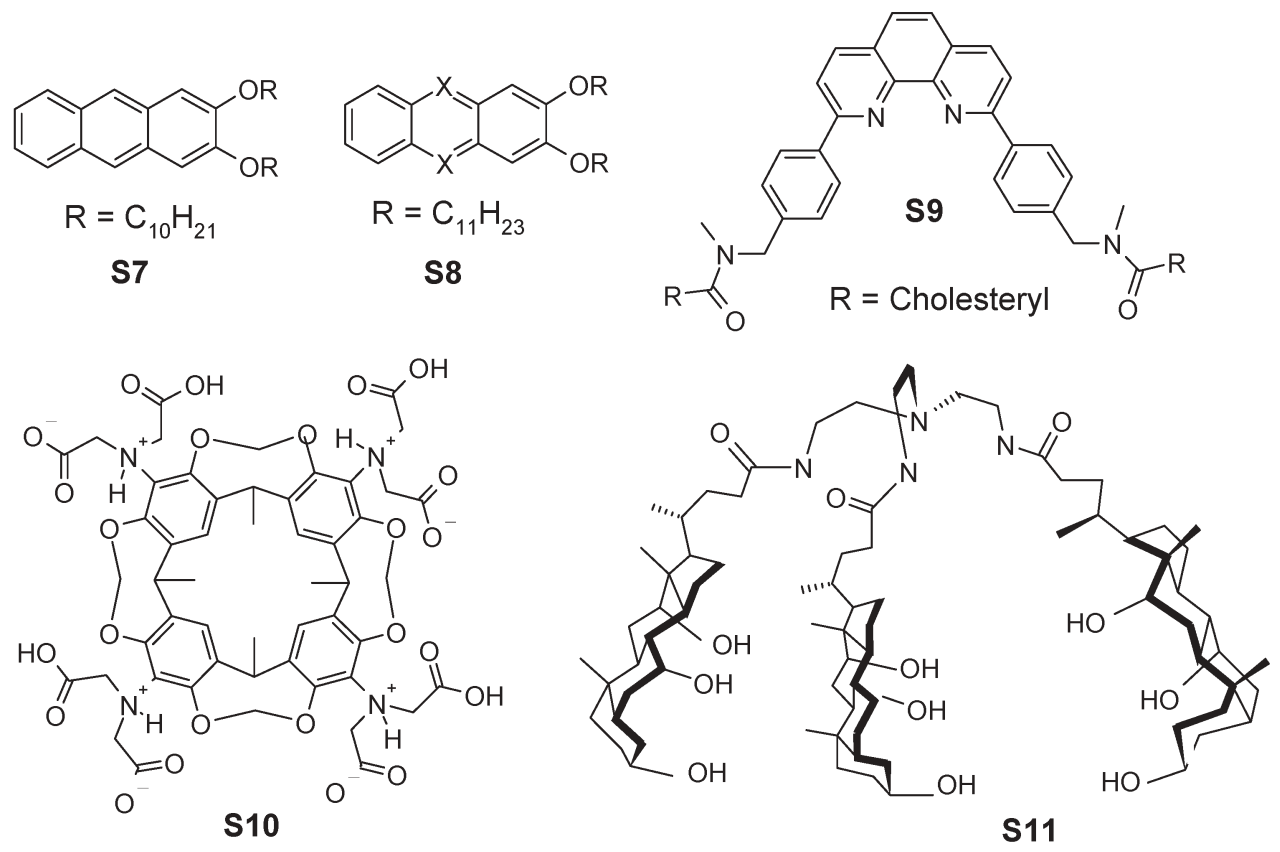

Chart 5 pH sensitive gelators.

produced a light blue sol (Fig. 4). The unprotonated and the protonated gelator molecules were found to emit at $396 \mathrm{~nm}$ and $530 \mathrm{~nm}$, respectively. Additionally, the fluorescence spectrum of the free gelator ( $\lambda_{\text {ext }} 285 \mathrm{~nm}$ ) overlaps with the absorption spectrum of the protonated form of the gelator. Thus, the color change observed between the gel and the sol states under UV has been attributed to an energy transfer from the free gelator to its protonated form. As a result of this energy transfer, the emission intensity of the protonated species $(530 \mathrm{~nm})$ in the organized gel state increased, resulting in the observed greenish yellow color.

A resorc[4]arene with four iminodiacetate groups on its upper rim (S10, Chart 5) gelled aqueous solutions. ${ }^{12}$ The gelator is soluble in neutral or basic aqueous solutions and gelation occurred when the $\mathrm{pH}$ of the solution was decreased to below 2.5. The gel formation could be controlled by altering the $\mathrm{pH}$ : the gel was dissolved by raising the $\mathrm{pH}$ and reformed by lowering the $\mathrm{pH}$. It was found that the process could be repeated several times until the concentration fell below the critical gelation concentration. The presence of transition metal ions such as $\mathrm{Cu}^{2+}, \mathrm{Co}^{2+}$ and $\mathrm{Fe}^{2+}$ was also shown to influence gelation. With copper the effect was so pronounced that the gelation ability of the resorc[4]arene was completely suppressed in the presence of two equivalents of cupric ion.

\subsection{Thermochromism by the incorporation of an additive in the gel}

Doping the gel with a suitable chromophore/dye that interacts with the molecular aggregates, and shows different colors in the sol and the gel states has led to the development of thermochromic gels. A pH sensitive dye, sodium salt of bromophenol blue incorporated into the hydrogel of a tripodal cholic acid derivative S11 (Chart 5) was green in color and changed to yellow upon melting to the sol. ${ }^{13}$ Bromophenol blue changes color from blue at $\mathrm{pH}>4.6$ to yellow at $\mathrm{pH}<3$ (Chart 6). The observed color change in the hydrogel is believed to be the result of a shift in the equilibrium between the two forms of the indicator, due to preferential incorporation of the blue form into hydrophobic pockets formed in the gel. As the concentration of the blue form increased in the gel state, it appeared green.

Color generation from alkylammonium polyoxomolybdate complexes incorporated in an organogel of trans-(1R,2R)-1,2bis(undecylcarbonylamino)cyclohexane could be controlled by sol-gel transition. ${ }^{14}$ When an appropriate mixture of the gelator and the molybdate complex were irradiated with UVlight, a blue color developed both in the sol and gel states. When the rate of fading of the color upon keeping the sample in dark was studied, the color fading in gel was found to be 26 times slower than in sol. The colored gel could be made colorless at a faster rate by heating it to a sol and then cooling to a gel. Furthermore, the color could be regenerated by irradiation, making the process reversible.

\subsection{Gelators with metal atoms (gelators with a metal center)}

Metallo-gelators are a class of gelators that contain metal ions. They give stimuli sensitive gels that undergo sol-gel phase transition when the redox state or the coordination number of the metal center changes. Such chemical changes have also been shown to lead to thermochromic gels.

The 2,6-bis(benzimidazolyl)-4-hydroxypyridine (BIP-OH) derivative of pentaethylene glycol (M1; Chart 7) gelled $\mathrm{CHCl}_{3} / \mathrm{CH}_{3} \mathrm{CN}$ in the presence of lanthanoid and transition metal ions. ${ }^{15}$ Gels prepared in the presence of a combination of ions such as $\mathrm{Co} / \mathrm{La}, \mathrm{Co} / \mathrm{Eu}, \mathrm{Zn} / \mathrm{La}, \mathrm{Zn} / \mathrm{Eu}$ could be dried and re-swollen by the addition of acetonitrile. The gel containing $\mathrm{Zn} / \mathrm{Eu}$ was photoluminescent and showed emission bands corresponding to Eu centered emission (Fig. 5). This emission 


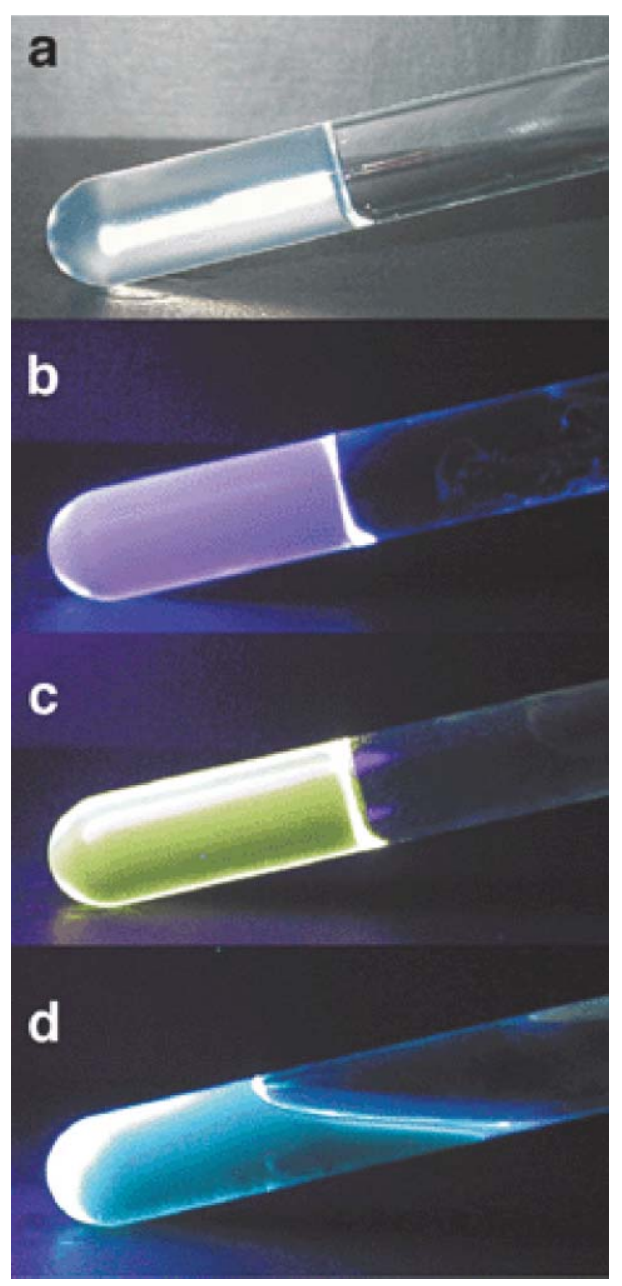

Fig. 4 Pictures of the propanol gel of $\mathbf{S 8}$ under normal light (a) and under UV irradiation (b); propanol gel + TFA (2 equiv.) under ambient conditions (c) and at $90{ }^{\circ} \mathrm{C}$ (d). Reproduced with permission from ref. $11^{\circ} 2003$ The Royal Society of Chemistry.

is due to the energy transfer from the ligand to the metal, giving a metal-centered emission ('antennae effect'). When a small amount of formic acid was added to the luminescent gel, the gel broke down and the Eu(III) emission was quenched. This is believed to result from the displacement of the BIP ligand by formate ions, which switches off the antennae effect. This process could be reversed by the evaporation of the solvent followed by re-swelling of the gel.

A heat-set gel (gelation induced by heating) formed from cobalt(II) complexes of 4-alkylated 1,2,4-triazoles (M2 and<smiles>O=S1(=O)OC(c2cc(Br)c(O)c(Br)c2)(c2cc(Br)c(O)c(Br)c2)c2ccccc21</smiles>

$\mathrm{SOL}$<smiles>O=C1C(Br)=CC(=C(c2cc(Br)c(O)c(Br)c2)c2ccccc2[N+](=O)[O-])C=C1Br</smiles>

GEL

Chart 6 Bromophenol blue.

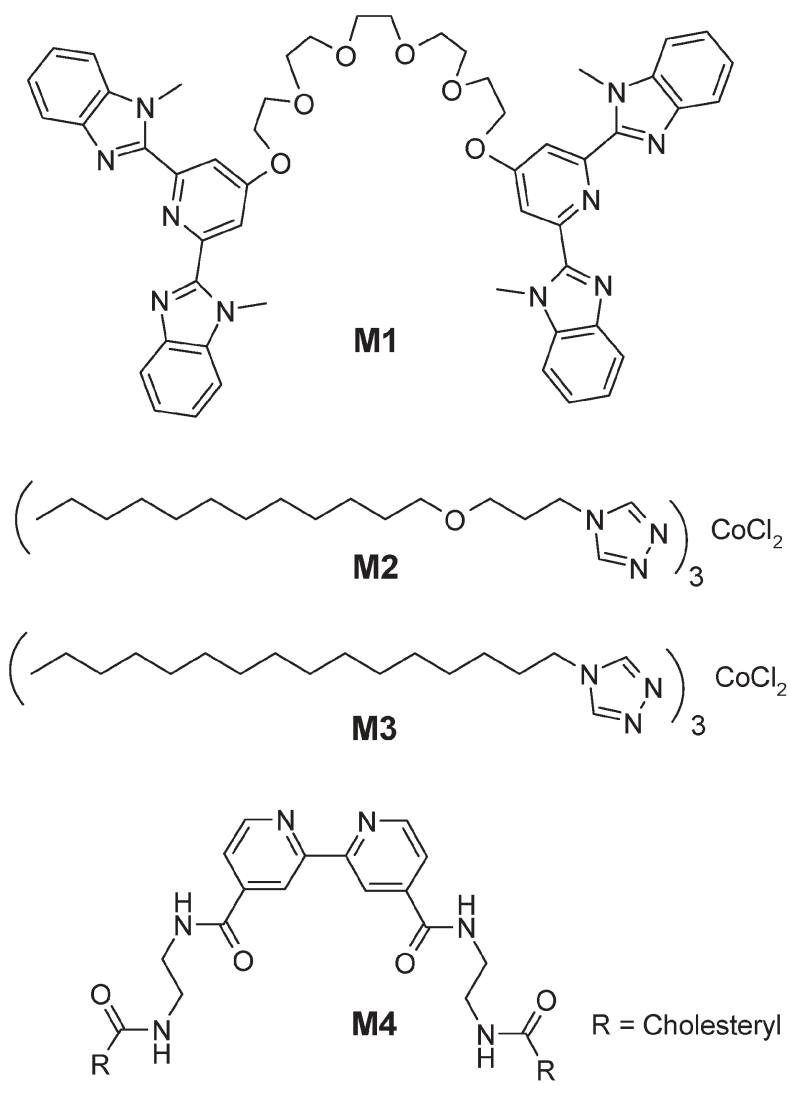

Chart 7 Metallogelators.

M3; Chart 7) showed thermochromic behavior. ${ }^{16} \mathrm{~A}$ blue gellike phase formed in chloroform at room temperature $\left(25^{\circ} \mathrm{C}\right)$ turned into a liquid upon cooling and eventually formed a pink solution at $0{ }^{\circ} \mathrm{C}$. The color change is caused by the conversion of the octahedral complex of cobalt in solution into a tetrahedral polymeric aggregate upon gelation.

A similar reversible color change was observed during the gel-sol transition of a gel derived from the $\mathrm{Cu}(\mathrm{I})$ complex of a 2,2'-bipyridyl derivative of cholesterol (M4; Chart 7) in 1-butyronitrile. ${ }^{17}$ The reddish brown sol of M4 turned into a

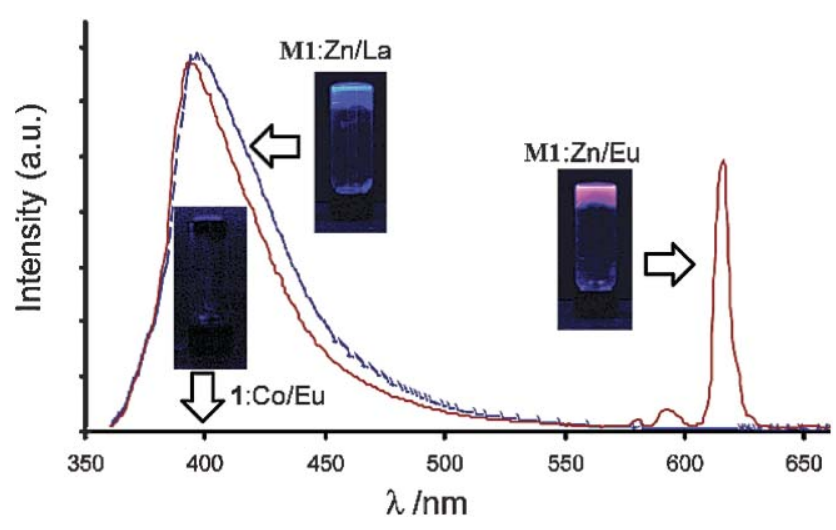

Fig. 5 Normalized photoluminescence spectra of the $\mathrm{CH}_{3} \mathrm{CN}$ swollen gels of M1: $\mathrm{Zn} / \mathrm{La}, \mathbf{M 1}: \mathrm{Zn} / \mathrm{Eu}$ and M1: $\mathrm{Co} / \mathrm{Eu}\left(\lambda_{\text {ex. }}=340 \mathrm{~nm}\right)$. M1: $\mathrm{Co} / \mathrm{Eu}$ gel shows no photoluminescence and lies at the baseline. Reproduced with permission from ref. $15^{\circ} 2003$ American Chemical Society. 
greenish blue gel upon cooling. It is believed that a distortion of the tetrahedral $\mathrm{Cu}(\mathrm{I})$ complex in the confined environment of the gel fiber is responsible for this color change. The gelation ability of this complex depends upon the oxidation state of copper and hence could be tuned by a redox process. Accordingly, heating the $\mathrm{Cu}$ (II) complex with ascorbic acid (to reduce $\mathrm{Cu}(\mathrm{II})$ to $\mathrm{Cu}(\mathrm{I})$ ) and cooling produced a greenish-blue gel. Heating this gel with the oxidant $\mathrm{NOBF}_{4}$ and cooling produced a sol with a small amount of blue precipitate.

\section{Supramolecular gels in electrooptics/photonics}

\subsection{Liquid crystalline physical gels (LC physical gels)}

Liquid crystalline physical gels are microphase-separated composites comprising a fibrous network of gel formed with a low molecular weight gelator, and the entrapped liquidcrystal molecules (mesogens) and the research in this area has been pioneered by the Kato group. ${ }^{18}$ LC physical gels, with liquid crystals phase-seggregated on the micrometer scale have been used in electro-optical displays in which they exhibit unique optical properties and dynamic functions due to the cooperative effects of liquid crystals and the fibrous network of gelators.

LC gels present two thermoreversible phase transitions: isotropic liquid-isotropic gel and isotropic gel-liquid crystalline gel as illustrated in Fig. 6 and these transitions take place independent of each other. The sol-gel and the isotropic-liquid crystalline phase transitions can be tuned by the choice of the gelator and the mesogen. The phase behaviour of a room temperature liquid crystalline gel of 4-cynano-4'-(pentyl)biphenyl (5CB, a nematic mesogen) and L-isoleucine derivative LC1 (Chart 8) is depicted in Fig. 7, which shows that the isotropic gel-anisotropic gel transition temperature $\left(35^{\circ} \mathrm{C}\right)$ is identical to that of 5CB alone. The gel of $\mathbf{L C 1}$ (at $0.25 \mathrm{~mol} \%$ of gelator) in a twisted nematic (TN) cell ${ }^{19}$ showed twisted nematic alignment and produced an electro-optic response of $6 \mathrm{~ms}$, which is twice as fast as the neat liquid crystal (5CB) at a similar threshold voltage. The nematic phase of $5 \mathrm{CB} / \mathrm{LC} 3$ (Chart 8) gel did not show TN alignment and that of $5 \mathrm{CB} / \mathrm{LC2}$ (Chart 8) gel phase separated macroscopically. ${ }^{20}$

Apparently, at higher percentages of the gelator (1.0$2.0 \mathrm{wt}^{\mathrm{t}} \%$ ), LC gels showed significant scattering due to the presence of larger amounts of the phase-separated material (fibrous aggregates) and were unsuitable for the TN mode. However, they could be conveniently used in the light scattering mode. When the LC gels of $5 \mathrm{CB}$ derived from LC1, LC2 and LC3 were examined for their light scattering

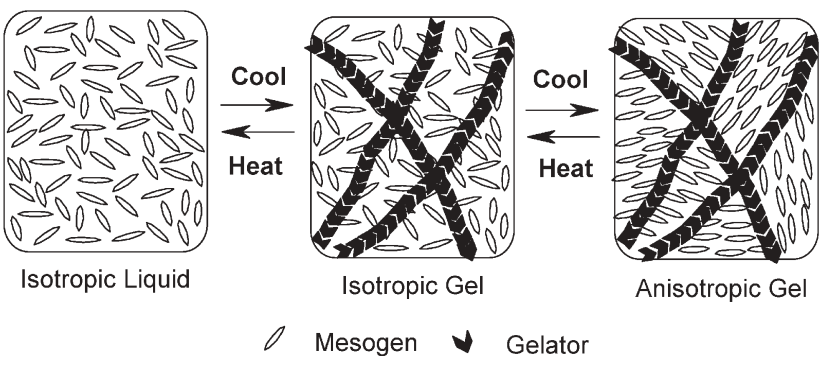

Fig. 6 Schematic of the formation of a liquid crystalline gel.
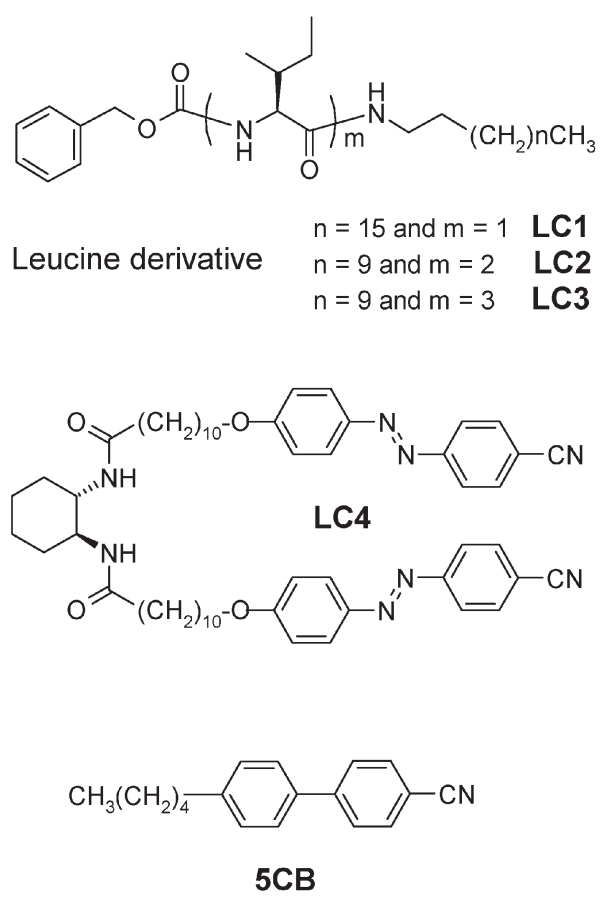

Chart 8 Gelators used to prepare liquid crystalline gels.

contrasts under an applied electric field, LC3 showed higher contrast switching between light scattering (OFF-state) and light transmitting states (ON-state) as compared with the other two. ${ }^{21}$ This was due to the differences in the pore sizes of the microphase-separated structure. The size of the LC domains formed in $\mathbf{L C} 3$ gel (fibre diameter $\sim 30 \mathrm{~nm}$ ) was $1-2 \mu \mathrm{m}$ and that of LC1 (fibre diameter $\sim 100 \mathrm{~nm}$ ) was $10 \mu \mathrm{m}$, while LC2 again separated macroscopically because of its instability, as mentioned earlier. Since light scattering takes place at the boundaries of the LC domains, the more finely dispersed LC3 network showed higher scattering. The switching between the scattering and the transmitting states of LC3 gel is illustrated in Fig. 8.

In the examples described above, the first phase transition is isotropic liquid-to-isotropic gel and the liquid-to-liquid crystalline phase transition of the mesogen occurred in the fibrous gel

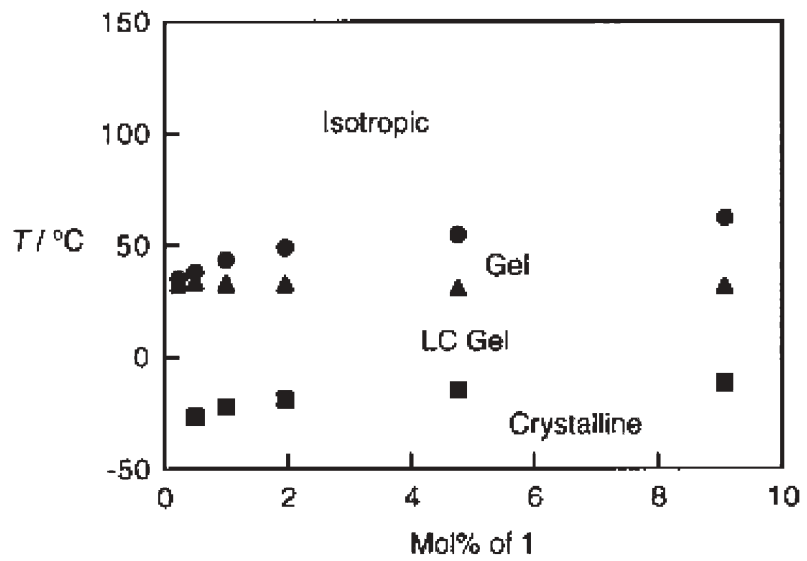

Fig. 7 Phase diagram of a liquid crystalline gel derived from LC1 and 5CB. Reproduced with permission from ref. $20^{\circledR} 1999$ Wiley VCH. 
(a)

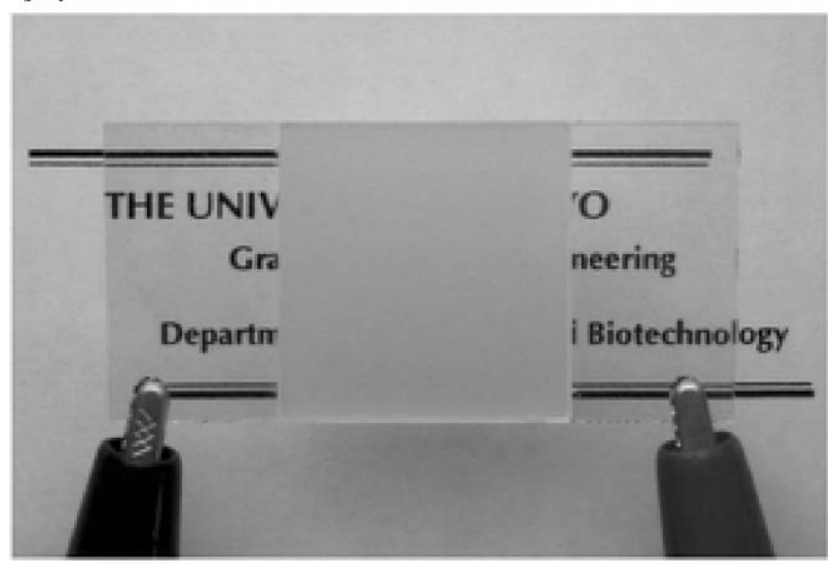

(b)

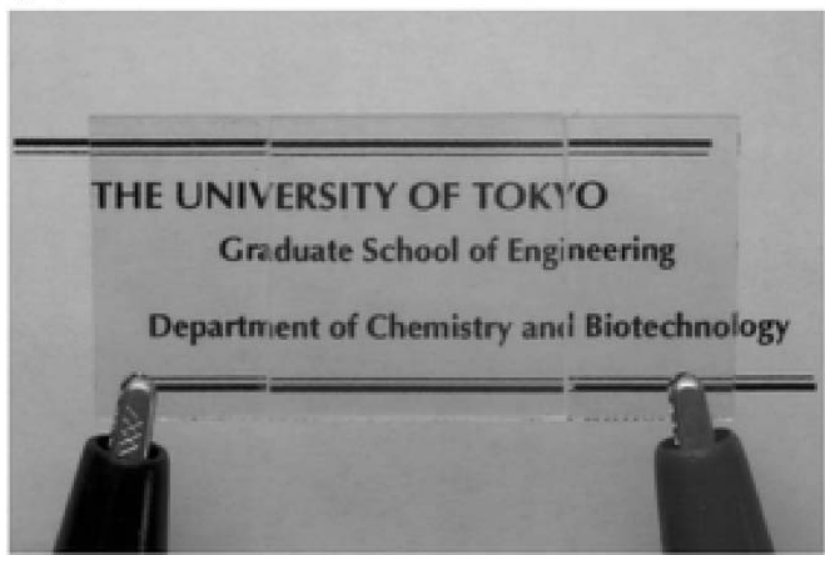

Fig. 8 Photographs of the liquid crystal cell filled with the gel of $\mathbf{5 C B}$ containing $0.2 \mathrm{wt} \%$ of $\mathbf{L C} \mathbf{3}$ in the (a) light scattering $(0 \mathrm{~V})$ and (b) light transmitting states $(70 \mathrm{~V})$. The distance between the cell and the displayed letters is $12 \mathrm{~mm}$. Reproduced with permission from ref. $21^{\circ}$ 2002 The Royal Society of Chemistry.

network. However, for the gelation of the ferroelectric liquid crystal SCE8 (which exhibits isotropic-nematic, nematicsmectic A, smectic A-smectic C phase transitions at 102, 78 and $58{ }^{\circ} \mathrm{C}$, respectively, upon cooling) by $\mathbf{L C 1}$, the transition from isotropic liquid to smectic liquid crystalline state precedes the sol-to-gel transition, the latter occurring within the range of smectic A and smectic C phases. The result was that the ordered liquid crystal acts as a template, leading to the formation of ordered gel fibres. ${ }^{22}$ The axes of the resulting gel fibres were found to be perpendicular to the direction of the long axis of the liquid-crystalline molecular order.

If the sol-gel transition in these anisotropic gels could be initiated by a factor other than temperature, the LC gels could exhibit new properties. The use of a photo-responsive gelator to obtain anisotropic gels has led to a material that can be used for re-writable information recording. The gelator used was a cyclohexane amide consisting of azobenzene moieties LC4 (Chart 8). ${ }^{23}$ When a nematic LC gel formed by LC4 and the room temperature nematic liquid crystal $5 \mathrm{CB}$ was irradiated with UV light, the trans to cis photoisomerization of the gelator molecules induced the transition of the nematic LC gel to a cholesteric LC sol. Thus, the photo-irradiation not only transformed the gel to the sol (the cis form does not have the capability to form an extended H-bonded network to give a gel), but also triggered the nematic to cholesteric phase transition in the LC phase. The cholesteric sol phase was found to exhibit a fingerprint texture of the cholesteric liquid crystal with a helical pitch of $c a .10 \mu \mathrm{m}$. It has been suggested that the formation of this cholesteric phase is induced by the chirality of the gelator molecule. When the LC cholesteric sol phase was kept at room temperature, or irradiated with weak visible light, the cis-form of the gelator underwent a slow transformation to the trans-form which associated to form gel fibres along the finger print texture, yielding a stable cholesteric gel. In essence, the cholesteric phase acts as a template for the self-assembly of the trans-gelator. The original nematic gel can be regenerated from this gel by a simple cycle of heating to the isotropic sol and cooling back to RT. Polarized optical micrographs along with a schematic for the various transformations are presented in Fig. 9. The same sequence of photoinduced transitions applied to a photomasked gel sample led to a patterning of the gel with alternating domains of fine nematic gels (masked part) and the finger print textures from the cholesteric gels (unmasked part). A schematic for the patterning process and optical micrographs obtained after a typical patterning cycle are presented in Fig. 10.

\subsection{Gel electrolytes}

Like their polymer counterparts, supramolecular organogels could be used as gel electrolytes since the 3D gel network offers no hindrance to the ionic diffusion in the entrapped liquid

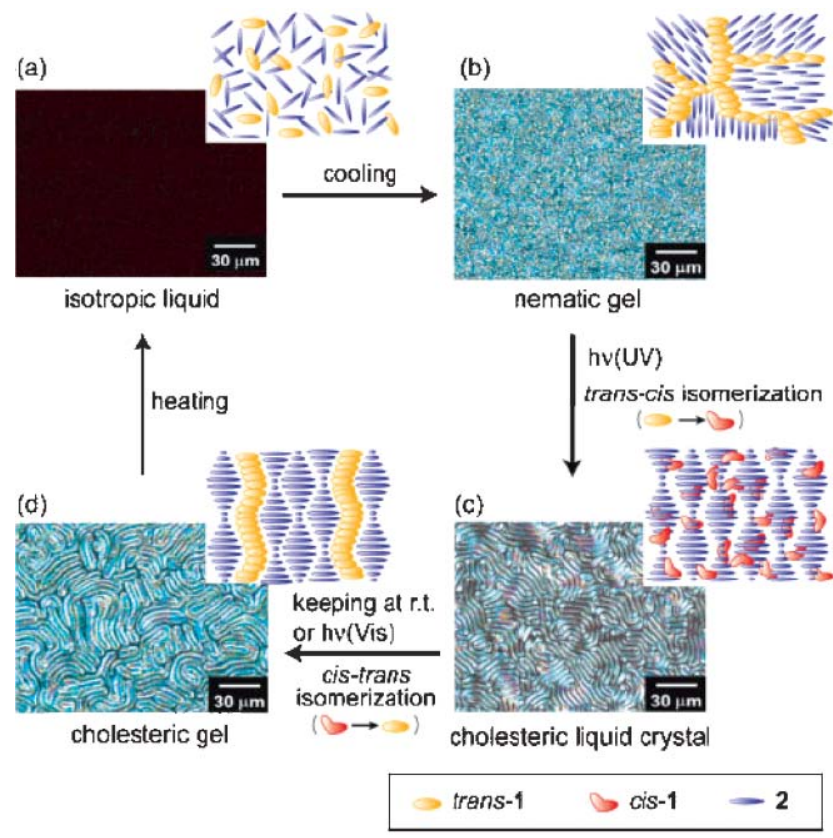

Fig. 9 Polarized optical micrographs and schematics of the disintegration and formation of the gel of $\mathbf{L C} \mathbf{4}$ and $\mathbf{5 C B}$. (a) Isotropic liquid at $120{ }^{\circ} \mathrm{C}$, (b) nematic gel at RT, (c) cholesteric LC sol phase at RT obtained by the UV irradiation of the nematic gel, and (d) cholesteric gel state at RT. Reproduced with permission from ref. $23^{\circ}$ 2003 Wiley VCH. 
(a)

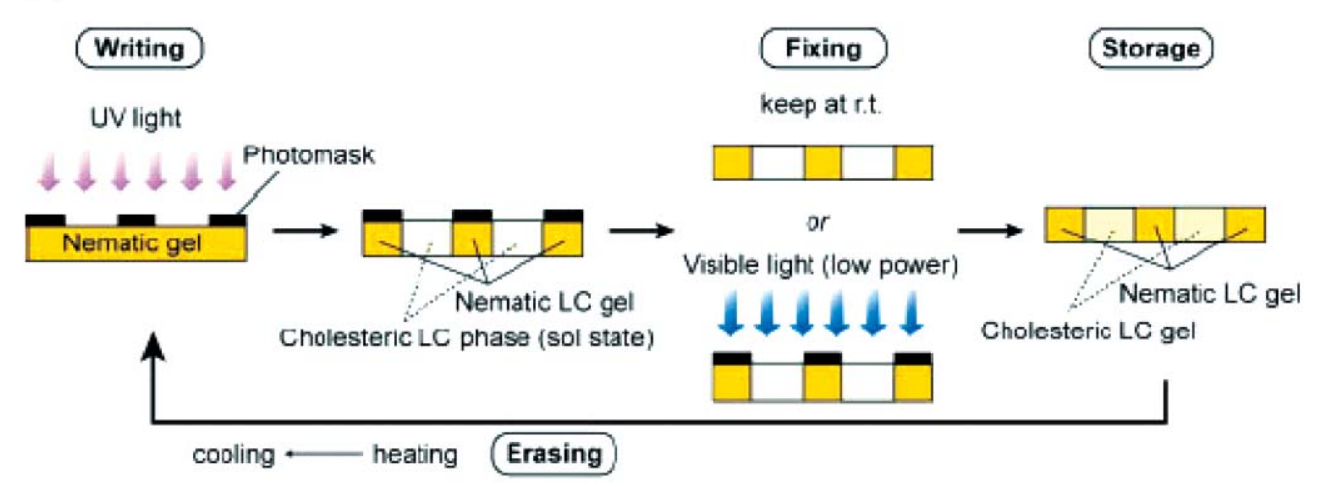

(b)

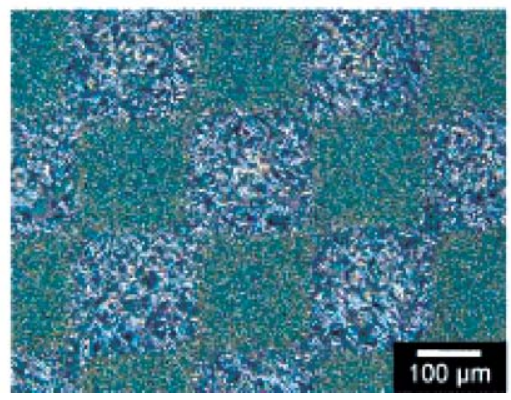

(c)

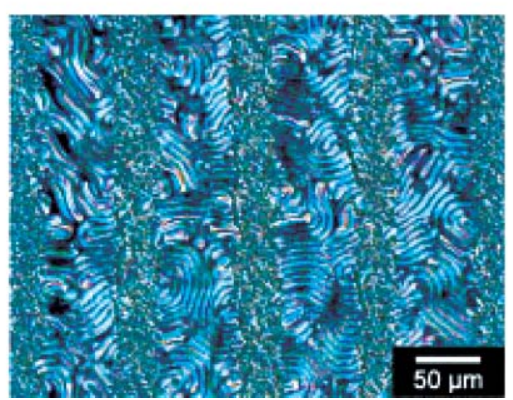

Fig. 10 (a) Schematic of the repetitive patterning process using the photo-responsive LC physical gels; (b) and (c) are the polarized optical micrographs of the patterned sample prepared by UV irradiation through a photomask of $200 \mu \mathrm{m}$ lattice and $50 \mu \mathrm{m}$ lines and spaces, respectively. Reproduced with permission from ref. $23^{\circledR} 2003$ Wiley VCH.

domain. For example, organogels derived from an isoleucine derivative in DMF, DMSO, or propylene carbonate containing supporting electrolytes such as $\mathrm{LiClO}_{4}, \mathrm{KClO}_{4}, \mathrm{LiCF}_{3} \mathrm{SO}_{3}$ and $(n-\mathrm{Bu})_{4} \mathrm{NClO}_{4}$ showed ionic conductivities similar to those of the corresponding isotropic solutions. ${ }^{24}$ Similarly, a gel of DDOA (S6) in propylene carbonate containing $\mathrm{Et}_{4} \mathrm{NBF}_{4}$ had an ionic conductivity similar to the parent electrolyte solution. ${ }^{25}$ Such gels have been used to fabricate dye-sensitized solar cells with promising results. For instance, a dyesensitized solar cell constructed using the room temperature ionic liquid (1-hexyl-3-methylimidazolium iodide), iodine and the isoleucine derivative as a quasi-solid-state electrolyte ${ }^{26}$ not only showed a high thermal stability but also a photovoltaic behavior similar to the non-gelled molten salt electrolyte (Fig. 11). The cell gave practical levels $(5 \%)$ of photovoltaic conversion under AM 1.5 irradiation. Likewise, an improved conversion of $6.1 \%$ was achieved with identical irradiation conditions, using a quasi-solid-state electrolyte system comprised of an amphiphilic ruthenium dye Z-907 and 1,3:2,4di- $O$-dimethylbenzylidene-D-sorbitol/3-methoxypropionitrile gel. $^{27}$

\subsection{Light harvesting}

Light harvesting is the spectacular function by which light harvesting complexes in photosynthetic organisms absorb sunlight and transfer to the reaction center where the photoinduced redox processes are initiated. A number of synthetic models have been developed to understand the light-harvesting phenomenon at the molecular level. These include dendrimers with the light absorbing chromophores organized on the periphery and chromophores organized in the form of molecular arrays, molecular complexes, self-assembled layers and self-assembled fibres (gels) ${ }^{26-28}$ The process involves absorption of photo-energy, followed by the transfer of the absorbed energy to a nearby secondary energy acceptor and efficient energy transfer requires a well-defined organization of the donor and the acceptor chromophores. In this context, it is

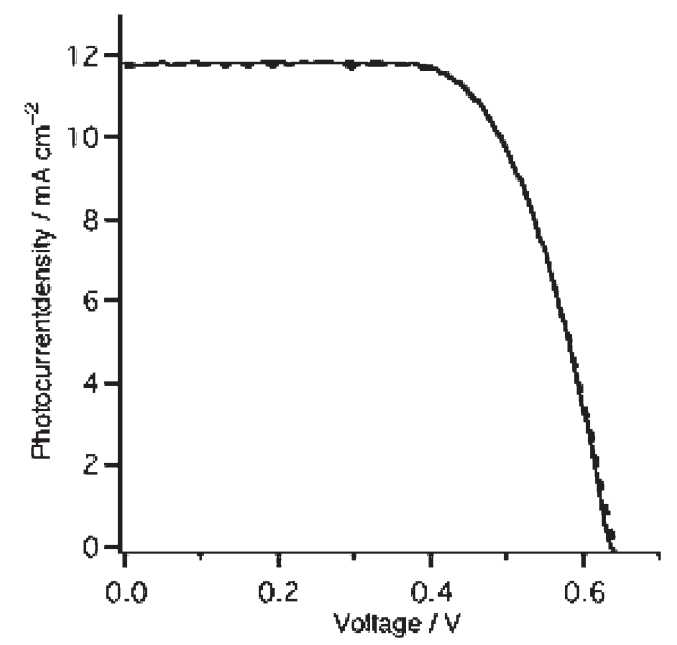

Fig. 11 Photocurrent-voltage curves of the cells with 1-hexyl-3methylimidazolium iodide containing $8.7 \mathrm{wt} \%$ of iodine under AM 1.5 irradiation; with (gelled molten salt electrolyte: solid curve) and without (molten salt electrolyte: dashed curve) $40 \mathrm{~g} \mathrm{~L}^{-1}$ of the gelator. Reproduced with permission from ref. $26^{\circ} 2002$ The Royal Society of Chemistry. 
quite interesting that the self-assembled fibrillar networks of chromophores exhibit light harvesting function, considering the ease with which these networks are constructed. Additionally, the energy transfer efficiency of the gel aggregates can be thermally controlled. Described below are three illustrative examples of light harvesting by gel assemblies.

An organogel derived from a $p$-phenylenevinylene derivative (LH1; Chart 9) doped with an organic dye (Rhodamine B) has been reported to harvest light. ${ }^{28}$ Fluorescent $p$-phenylenevinylene derivatives (e.g., LH1) gelled hydrocarbons such as hexane, cyclohexane, benzene, and toluene via $\mathrm{H}$-bonding and $\pi-\pi$ interactions. The self-assembled superstructures formed on gelation were capable of thermoreversibly transferring fluorescence resonance energy to the acceptor Rhodamine B dispersed in the gel network. Fig. 12 shows the good overlap between the emission and absorption spectra of aggregated LH1 and Rhodamine B respectively. Consequently, irradiation of the gel at the excitation wavelength $(380 \mathrm{~nm})$ of the $p$-phenylenevinylene derivative in the presence of Rhodamine B led to selective quenching of the LH1 fluorescence between 500-650 nm (resulting from LH1 aggregates) with a concomitant increase in the dye emission at $620 \mathrm{~nm}$ (Fig. 13). Upon heating the gel, the dye emission decreased considerably<smiles>[R]Oc1cc(/C=C/c2cc([R])c(CO)cc2O[R])c([R])cc1/C=C/c1cc(O[R])c(CO)cc1[R]</smiles>

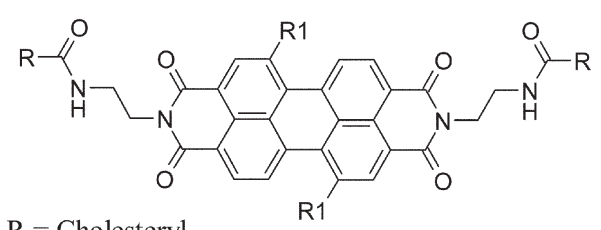

$\mathrm{R}=$ Cholesteryl

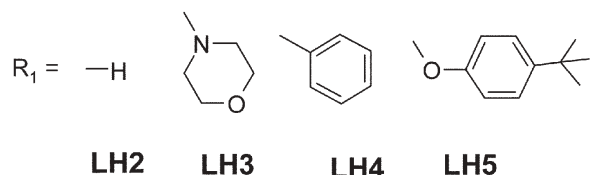

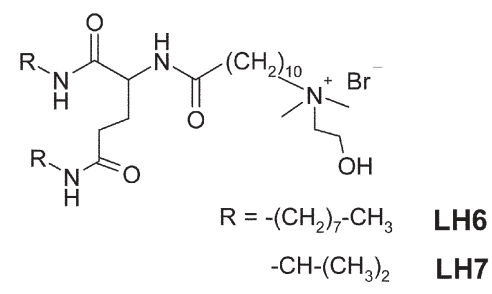<smiles>COc1c2ccccc2c(OC)c2cc(S(=O)(=O)O[Na])ccc12</smiles>

Naphthalene sulfonate

Anthracene sulfonate

Chart 9 Gelators that organize into light harvesting architectures.

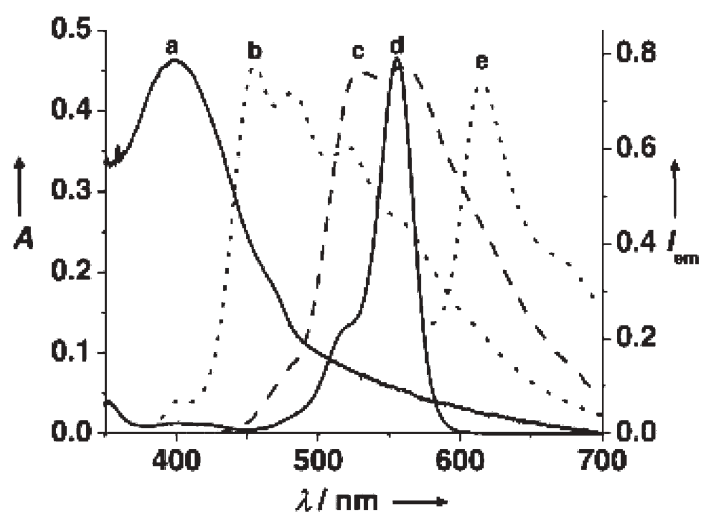

Fig. 12 Absorption and emission spectra of LH1 and Rhodamine B in cyclohexane : chloroform $(16: 1)$. (a) Absorption of LH1, (b) emission of monomeric LH1 at $380 \mathrm{~nm}$ excitation, (c) emission of selfassembled LH1 gel at $470 \mathrm{~nm}$ excitation, (d) absorption of Rhodamine $\mathrm{B}$, (e) emission of Rhodamine $\mathrm{B}$ at $535 \mathrm{~nm}$ excitation. Reproduced with permission from ref. $28^{\circ} 2003$ Wiley VCH.

while the emission from the molecular LH1 increased, suggesting that the energy transfer occurred almost exclusively from the self-assembled aggregates of LH1. Interestingly, the efficiency of energy transfer was good even in a dried film.

A similar light harvesting function was observed in the gelled perylene-based cholesterol derivatives LH2-LH5 (Chart 9). ${ }^{29}$ Perylene derivatives absorb a wide range of visible light energy depending on their substituents. When gels were formed from a mixture of two or more different perylene derivatives and irradiated, an energy gradient was established in which the excitation energy of one derivative was passed on to the other, and then to the next one, in a stepwise manner. No light harvesting was observed in the sol phase as in the previous example.

In an interesting study, energy transfer from chromophores organized on the gel fibres to another dispersed in the solvent

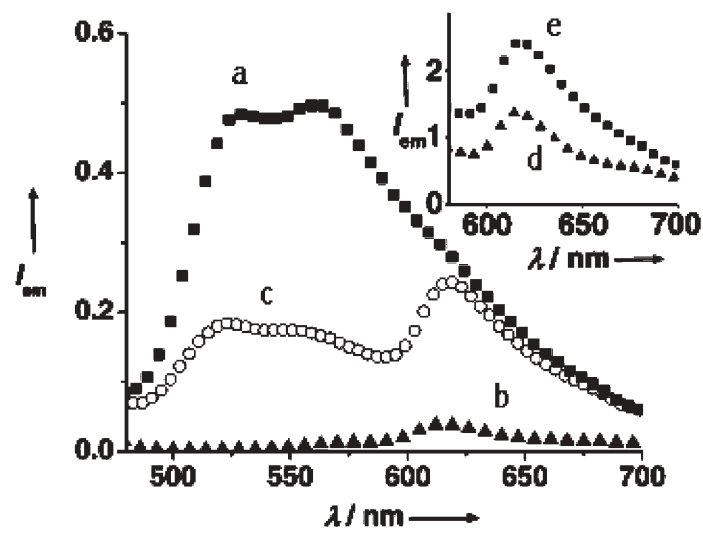

Fig. 13 Energy-transfer quenching of the fluorescence of LH1 $\left(1.01 \times 10^{-5} \mathrm{M}\right)$ in cyclohexane : chloroform $(16: 1)$ in the presence of Rhodamine B $\left(8 \times 10^{-5} \mathrm{M}\right)$ a) at an excitation wavelength of $470 \mathrm{~nm}$. (a) fluorescence of LH1, (b) fluorescence of Rhodamine B, (c) fluorescence of LH1 + Rhodamine B. Inset shows the emission of the dye on its indirect excitation at $470 \mathrm{~nm}$ (e) and $535 \mathrm{~nm}$ (d) illustrating the amplified emission. Reproduced with permission from ref. $28^{\circledR}$ 2003 Wiley VCH. 
pool has been demonstrated. A hydrogel obtained from a mixture of cationic glutamate derivatives, LH6 or LH7 (Chart 9), and the anionic naphthalene sulfonate (5 mM) and anthracene sulfonate $(1 \mathrm{~mol} \%)$ exhibited light harvesting. ${ }^{30}$ The naphthalene anions, believed to be organized on the surface of the gel fibres, channelled their excitation energy to the anthracene anions present in the aqueous pool resulting in the emission from anthracene.

\section{Molecular gels as structure directing agents for the synthesis of nanoporous materials}

Molecular gels provide a diversity of architectures such as rods, ribbons, tapes, tubes, helices etc. in nanometric dimensions. The superstructures formed by a given gelator molecule define a unique morphology, which can be used as templates for transcribing into a range of inorganic materials for potential applications (such as in catalysis and in separations).

Thus, a variety of porous inorganic materials (superstructures) have been prepared by the sol-gel polymerization of metal alkoxides in organogels. Among these, the preparation of nano-structured silica has been studied extensively. In a typical transcription procedure, an organogel is formed in the presence of tetraethyl orthosilicate (TEOS) as the silica precursor, and a catalyst to hydrolyze the TEOS. The hydrolysis of TEOS followed by the polycondensation of silicate around the gel fibre leads to a silica gel which is dried. The subsequent removal of the organic materials by washing with a suitable organic solvent or calcining yields porous silica.

For an efficient transcription of the gel fibre structure onto silica, an effective interaction between the organogel fibres and the silica precursor is necessary. Hence for acidic conditions of sol-gel polycondensation, when anionic silicate species are present in the system, the gelator should either be cationic, or doped with a cationic analogue in appropriate proportions. Under basic conditions, H-bonding groups present on the gel fibres can interact with the silica precursor and promote good transcription. Shinkai et al. have created a variety of silica architectures resembling tubes, rolled paper, lotus-shape etc., via sol-gel polymerization of TEOS in organogels of cholesterol-crown, sugar and porphyrin derivatives. ${ }^{31}$ For example, 1-O-methyl-4,6- $O$-benzylidene derivatives of glucose, galactose and mannose which gel a variety of solvents were rendered suitable for conditions of sol-gel transcription of silica by the incorporation of amino groups. The modified gelators gelled solvents such as $\mathrm{CS}_{2}, \mathrm{CCl}_{4}$, toluene, ethanol, 1-butanol, 1-octanol and EtOAc. sol-gel polymerization of TEOS in the ethanol gel phase followed by calcination provided mesoporous silica. ${ }^{32}$ The success in the transcription of chiral helical fibres onto silica is particularly interesting. Both right and left handed helical silica structures (Fig. 14) were obtained by the sol-gel transcription of the helical aggregates of fibres formed by mixtures of trans-( $1 R, 2 R)$ - and trans-(1S,2S)-1,2-diaminocyclohexane derivatives $\mathbf{T} 1$ and their cationic analogs $\mathbf{T} 2$ (Chart 10). ${ }^{33}$ The chirality of the organogels formed with mixtures of T1(S) + T2(S) and T1(R) + T2(R) was established by circular dichroism measurements. The helical sense of the silica fibres [left-handed and right-handed silica, respectively, from the mixtures of $\mathbf{T 1}(\mathbf{R})+$

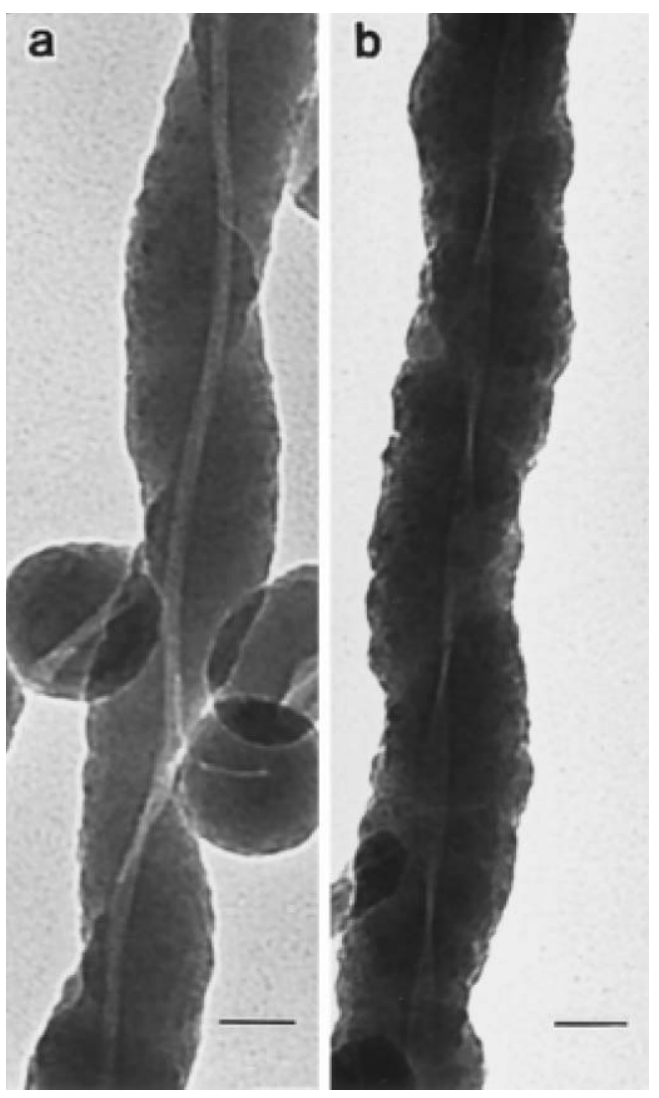

Fig. 14 TEM pictures of the silica obtained by sol-gel transcription of (1 : $1 \mathrm{wt} \%)$ organogels of (a) left-handed $\mathbf{T} 1+\mathbf{T} 2$ and (b) righthanded $\mathbf{T} 1+\mathbf{T} 2$. Reproduced with permission from ref. $33^{\bullet} 2000$ American Chemical Society.

T2(R) and T1(S) + T2(S)] obtained after sol-gel transcription agreed very well with that observed with the xerogels. Even double helical silica superstructures have been prepared by transcribing the organogel fibres of a cationic gemini surfactant. $^{34}$

Helical tubes of transition metal oxides were prepared by using helical fibres of 1,2-diaminocyclohexane analogues as templates. ${ }^{35}$ Compound T3 (as the perchlorate salt; Chart 10) gave chiral fibrous aggregates in ethanol and the sol-gel polymerization of metal alkoxides of titanium, tantalum and vanadium was done on these chiral fibres. Basic hydrolysis of a mixture containing the metal alkoxides and the gelator in ethanol resulted in helical metal oxide structures. A typical TEM picture obtained for the tantalum oxide fibres with the right-handed and left-handed helicity, prepared using the $R, R$ and $S, S$ - enantiomers as the gelators, respectively, is shown in Fig. 15.

Aqueous gel of a tripodal bile acid derivative S11 (Chart 5) has been used to prepare nanotubes of silica, and a number of metal oxides and sulfates like $\mathrm{TiO}_{2}, \mathrm{ZrO}_{2}, \mathrm{ZnO}, \mathrm{WO}_{3}, \mathrm{BaSO}_{4}$ and $\mathrm{ZnSO}_{4}{ }^{36}$

Silica fibres functionalized with organic groups have been obtained by the co-condensation of TEOS and organotriethoxysilanes like phenyltriethoxysilane (PTES) and aminopropyltriethoxysilane (APTES) using organogel derived from S7 (Chart 5) as template. ${ }^{37}$ The hybrid material consisted of 

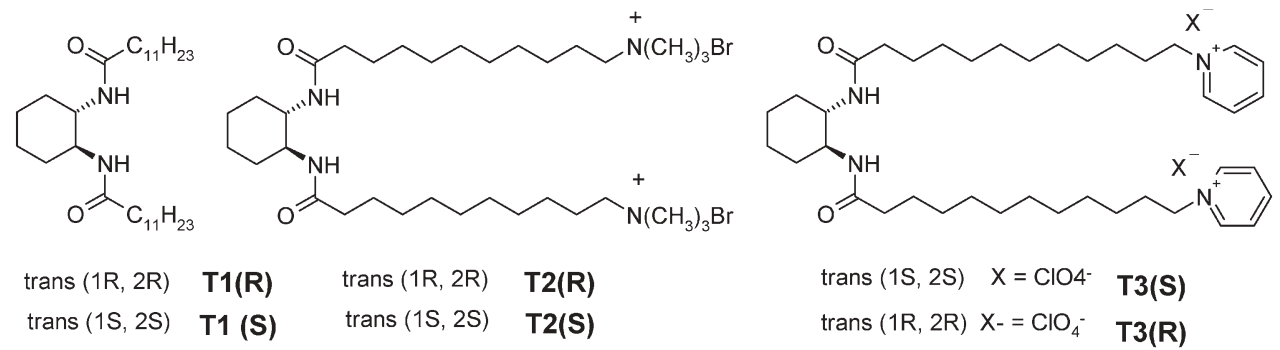<smiles>CCO[SiH2]CCCNC(=O)N[C@H]1CCCC[C@H]1NC(=O)NCC[SiH2]OC</smiles><smiles></smiles><smiles>C=C(C)C(=O)OCCOC(=O)CCNC(=O)N[C@H]1CCCC[C@@H]1NC(=O)NCCC(=O)OCCOC(=O)C(=C)C</smiles><smiles></smiles>

Chart 10 Gelators used to construct template architectures.

anisotropically distributed fibrous bundles. After removal of the template (fibres of S7) the presence of organic functionality (phenyl and amino groups) was confirmed by FT-IR measurements and chemical analysis. Finally, the accessibility of the grafted aminopropyl groups on the silica was proved by the formation of a Schiff's base with benzaldehyde.
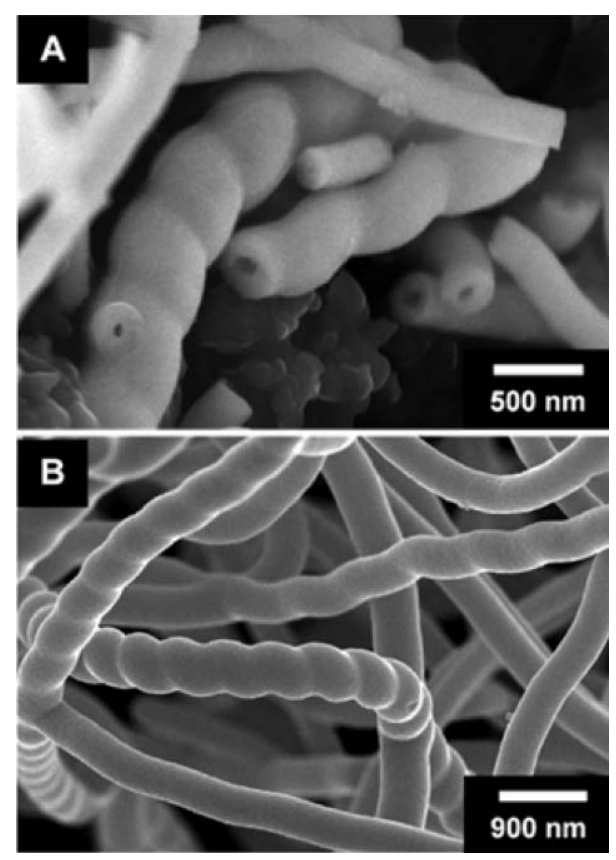

Fig. 15 SEM images of tantalum oxide fibers obtained from (A) $(R, R)$-enantiomer and (B) $(S, S)$-enantiomers of T3. Reproduced with permission from ref. $35^{\circ} 2002$ American Chemical Society.
Hybrid organic-inorganic materials with helical morphologies were created by the acid hydrolysis of the silylated analogue (T4; Chart 10) of an organogelator in aqueous medium. Right and left handed helical morphologies were observed for the hybrid gels obtained from $R, R$ - and $S$, $S$-derivatives, respectively. ${ }^{38}$

Similarly, hybrid gels with reinforced mechanical strength have been obtained by the hydrolysis of a silylated porphyrinbased gel. The gel derived from the $\mathrm{Cu}(\mathrm{II})$ complex of a silylated porphyrin T5 (Chart 10) had a fibrous morphology as opposed to the sheet-like structures formed by the uncomplexed derivative. When the gel formed from the copper complex of $\mathbf{T 5}$ in anisole was subjected to hydrolysis, a hybrid gel whose elasticity was increased by 14 fold was obtained.

\subsection{Polymerized and reverse aerogels}

The molecular imprinting approach has been used to make materials such as polymerized and reverse aerogels, using organogels. $^{39-41}$ These materials were prepared by the polymerization of gelled polymerizable solvents such as methyl methacrylate or styrene in the presence of a cross-linking agent such as divinylbenzene. After leaching out of the gelator, porous structures with submicron dimensions were obtained. These materials with well-defined pore sizes reflecting the dimensions of the gel network structure have potential application as membranes and separating agents, and as insulators. Alternatively, if the gelator itself is polymerizable, then polymerization can be carried out in the gelled state to yield a porous polymer network upon evaporation of solvents. In an interesting study, the physical gel formed from a polymerizable $(1 R, 2 R)$-1,2-bis(ureido)cyclohexane derivative 


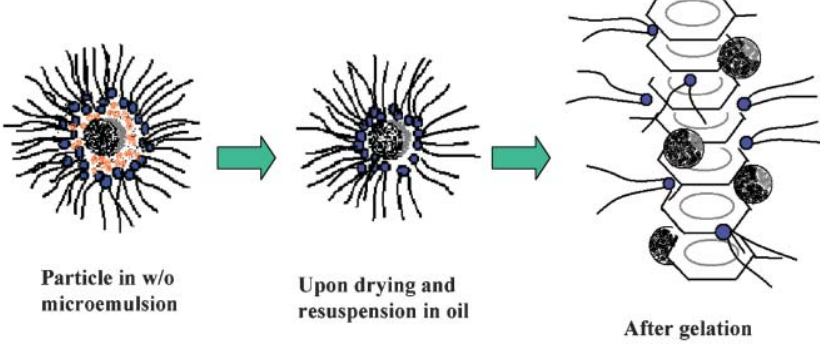

Fig. 16 Schematic representation of the strategy employed to incorporate nanoparticles synthesized in water-in-oil microemulsion into gel fibres.

T6 (Chart 10) incorporated with $5 \mathrm{~mol} \%$ of the photoiniator 2,2-dimethoxy-2-phenylacetophenone was photopolymerized to obtain a more stable polymer gel. Subsequent freeze-drying provided a low-density organic aerogel, which could be swollen with other solvents such as methanol and $\mathrm{CHCl}_{3}$ to give transparent gels. ${ }^{42}$

Very recently Shinkai et al. have prepared sulfonated polyaniline superstructures by using an organogel superstructure formed from the DMSO gel of chiral T1/T2 (Chart 10) as the template. ${ }^{43}$ The formation of the sulfonated polyaniline superstructure relied on an effective electrostatic interaction between the cationic gelator and the anionic sulfonated polyaniline leading to the assembly of the sulfonated polyaniline on the organogel superstructure.

\subsection{Molecular gels as templates for assembling nanoparticles.}

Of late there has been considerable interest to assemble nanoparticles into two or three-dimensional architectures, as these materials are potentially useful for the construction of electronic and optical devices. ${ }^{44}$ The fibre of supramolecular gels have been used as templates to assemble nanoparticles.

Superparamagnetic ferrite nanoparticles and photochromic CdS nanoparticles have been organized on the fibres of
AOT-Phenol (Chart 1) physical gels. ${ }^{45}$ This was achieved by the simple conversion of a nanoparticle containing water-in-oil microemulsion of AOT into a gel by the addition of phenol (Fig. 16). Nanoparticles were first prepared in an AOT waterin-oil microemulsion, which was dried to remove the moisture. Reconstitution of the reverse micelle with the nanoparticle in its core by the addition of isooctane followed by the addition of phenol resulted in an organogel with nanoparticles trapped in the gel fibres. Fig. 17 shows AFM images of the ferrite nanoparticles assembled on the gel fibres. The nanoparticles embedded in the gel fibres confer magnetic and luminescent properties to the gel and these composites have considerable application potential.

Using a different strategy, fibres of an organogel derived from a thiol terminated trans-1,2-bis(alkylamide)cyclohexane based gelator were used to organize gold nanoparticles. ${ }^{46}$ The preparation involved heating a degassed octanethiol-stabilized gold nanoparticle solution in toluene with the gelator to $65^{\circ} \mathrm{C}$, and cooling the mixture to give a brown-colored gelnanoparticle composite. SEM images obtained without the use of a staining agent showed gold nanoparticles attached to fibers. The organization of nanoparticles on the gel fibre was a result of a simple site-exchange reaction of the thiol group in the gelator with the octanethiol on the surface of the stabilized gold nanoparticles.

\section{Others}

Supramolecular organogels have long been used in lubrication industry. ${ }^{2 a}$ The aluminium salt of dihexadecyl phosphate and the cobalt salt of monooleate thicken organic solvents and have been used as lubricants. Lithium 11-hydroxystearate is also a commonly used lubricant. Organogels have been used in cosmetic formulations. ${ }^{47}$ The gelation of cryogenic propellants has attracted considerable interest since it helps to reduce leakage and offers increased safety and fuel density. Some of the low mass gelators are potential candidates for this purpose.

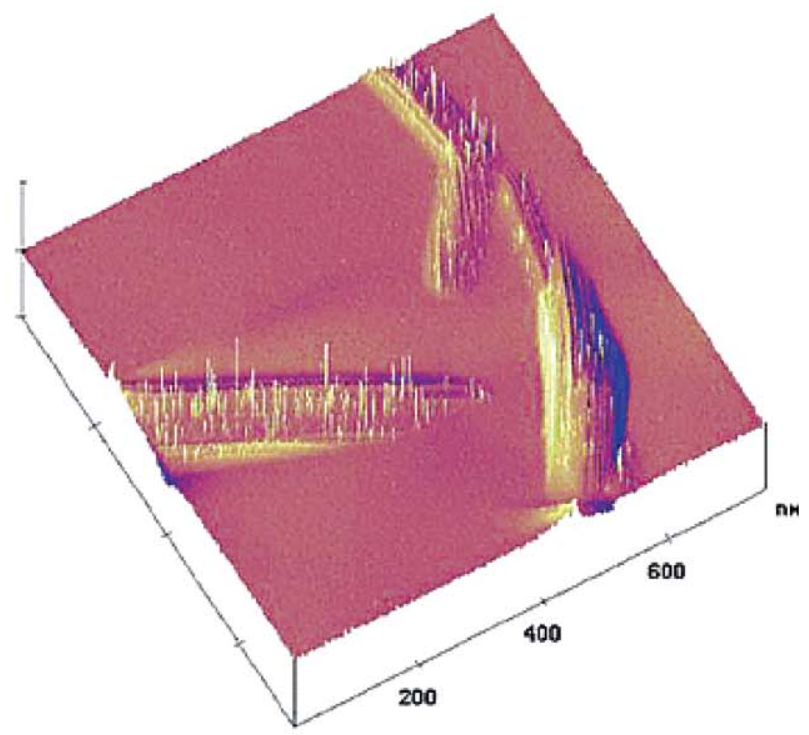

Fig. 17 (a) Atomic force microscopy images of the AOT-phenol gel containing ferrite nanoparticles (b) illustration of streaks obtained as a result of uncompensated changes in tip-sample force interactions. Reproduced with permission from ref. $45^{\circ} 2002$ American Chemical Society. 


\section{Supramolecular gels for oil recovery}

Supramolecular organogelators could be used for the treatment of oil spillages and safer disposal of used domestic oils. Simple derivatives of alanine selectively gel oil from oil/water mixtures. ${ }^{48}$ Selective gelation of the oil layer in an oil/water mixture occurred upon the addition of the solid gelator and heating followed by equilibration. A similar observation was made with dicyclohexylammonium salt of 4-chlorocinnamic acid. $^{49}$ This gelator is sparingly soluble in water and but completely miscible in water-MeOH mixtures. Yet, an equilibrated biphasic mixture of petrol/water led to the preferential gelation of the organic phase even in the presence of a few drops of methanol.

\section{Biomedical applications}

Hydrogels of natural and synthetic polymers are being widely explored as media for tissue engineering, owing to their structural similarity to the macromolecular components in the body. $^{50}$

As many supramolecular hydrogels are derived from naturally occurring molecules, they are likely to be biocompatible and may therefore be explored for similar applications.

Also, gels are promising media for applications involving controlled release of molecules, specifically for drug delivery. Site-specific controlled release of drugs is an important issue in current therapeutics and programmed delivery of a pharmaceutically active agent may be achieved by the use of stimuli sensitive gels as drug delivery agents. A few efforts have been made to investigate supramolecular gels for their drug delivering potential, which are discussed in the following.

Multicomponent organogels of sorbitan monostearate containing niosomes (vesicle in water) has been investigated for their in vivo drug delivery capability. ${ }^{51}$ Model antigens bovine serum albumin (BSA) and haemagglutinin (HA) used for depot and immunogenicity studies, respectively, were entrapped in the vesicle prior to gel formation. A short-lived depot effect was observed following the administration of the BSA containing gel into rats. The antigen cleared from the injection site over a period of days. Gels containing HA showed immunoadjuvant properties and enhanced the primary and secondary humoral immune responses to the antigen, HA.

The release of model drugs, 8-aminoquinoline (AQ) and 2-hydroxyquinoline (HQ) from the hydrogel of $N, N^{\prime}$-dibenzoyl-L-cystine has been studied in vitro. ${ }^{52}$ The rate of drug release depended on the gelator-drug interaction - the release of $\mathrm{HQ}$ being faster than that of $\mathrm{AQ}$, which binds more strongly to the gel strands via an additional electrostatic H-bonding. The initial release rate of AQ (but not with HQ) from the gel was proportional to the rate of gel degradation, as observed with biodegradable polymer gels. The release process was found to be independent of the gelator concentration (in a narrow range) or the aqueous medium. These encouraging results point at the promise held by molecular gels for controlled drug delivery.

The well-known antibiotic vancomycin functionalized with pyrene was found to be a hydrogelator. ${ }^{53}$ Interestingly, the gelator molecules assembled in the form of helical ribbons in the aqueous gel exhibited improved antibiotic activity. Such gels can potentially be used for wound dressing.

\section{Supramolecular gels as media}

Supramolecular gels may be used as media for crystal growth. Crystals grown from gel have improved physical properties compared to crystals grown from solutions and gels have been used as media to grow large organic, inorganic and macromolecular crystals of high optical quality. ${ }^{54}$ Semi-wet peptide/protein microarrays of a supramolecular hydrogel derived from glycosylated aminoester has been used for highthroughput analysis of protein/enzymes. ${ }^{55}$ A semi-wet sensor chip developed by incorporating artificial receptors within the same gel was useful for high throughput analysis of analytes (anions/metal ions). ${ }^{56}$

Supramolecular gel matrices, especially the hydrophobic domains of the hydrogels, could be used as constrained nanoreactors. They might affect the kinetics of the reaction and isomeric distribution of the products depending upon the geometrical constraints of the hydrophobic patches. Not much activity has been seen in this area so far.

\section{Conclusions}

The review covered some of the developments in the field of supramolecular gels for targeted applications. The promise offered by these novel materials is immense and perhaps many possible applications of supramolecular gels will emerge in the near future. An issue that must be addressed for a variety of applications is the long-term stability of gels. Some of the biological applications require bringing down the sol-gel transition temperatures while simultaneously increasing the gel stability and strength. Also, a greater emphasis needs to be given to understand the organization of these small organic molecules and their properties in order to facilitate more rational approaches for their exploitation.

Supramolecular gels may replace liquids in many of the technological applications in the not-so-distant future!

\section{References}

1 Y. Osada and K. Kajiwara, (ed.), T. Fushimi, O. Hirasa, Y. Hirokawa, T. Matsunaga, T. Shimomura and L. Wang, (assoc. ed.), H. Ishida, (translator) Gels hand book, Vol. 1-3, Academic Press, San Diego, 2001.

2 For reviews on low molecular mass organic gelators, see: $(a)$ P. Terech and R. G. Weiss, Chem. Rev., 1997, 97, 3133; (b) L. A. Estroff and A. D. Hamilton, Chem. Rev., 2004, 104, 1201.

3 A notable group of low molecular mass natural products that form gel are some of the bile acids. For leading references see: S. Mukhopadhyay and U. Maitra, Curr. Sci., 2004, 87, 1666.

4 Gelation of an aqueous solution of lithium urate was reported by von A. Lipowitz, Ann. Chem. Pharm., 1841, 38, 348.

5 O. Gronwald and S. Shinkai, Chem. Eur. J., 2001, 7, 4329 and references therein.

6 K. Murata, M. Aoki, T. Nishi, A. Ikeda and S. Shinkai, J. Chem. Soc., Chem. Commun., 1991, 1715.

7 M. Ayabe, T. Kishida, N. Fujita, K. Sada and S. Shinkai, Org. Biomol. Chem., 2003, 1, 2744.

8 S. A. Ahmed, X. Sallenave, F. Fages, G. Mieden-Gundert, W. M. Müller, U. Müller, F. Vögtle and J.-L. Pozzo, Langmuir, 2002, 18, 7096.

9 J. J. D. de Jong, L. N. Lucas, R. M. Kellogg, J. H. van Esch and B. L. Feringa, Science, 2004, 304, 278. 
10 J.-L. Pozzo, G. M. Clavier and J.-P. Desvergne, J. Mater. Chem., $1998,8,2575$.

11 K. Sugiyasu, N. Fujita, M. Takeuchi, S. Yamada and S. Shinkai, Org. Biomol. Chem., 2003, 1, 895.

12 S. R. Haines and R. G. Harrison, Chem. Commun., 2002, 2846.

13 U. Maitra, S. Mukhopadhyay, A. Sarkar, P. Rao and S. S. Indi, Angew. Chem. Int. Ed., 2001, 40, 2281.

14 T. Yi, K. Sada, K. Sugiyasu, T. Hatano and S. Shinkai, Chem. Commun., 2003, 344.

15 J. B. Beck and S. J. Rowan, J. Am. Chem. Soc., 2003, 125, 13922.

16 K. Kuroiwa, T. Shibata, A. Takada, N. Nemoto and N. Kimizuka, J. Am. Chem. Soc., 2004, 126, 2016.

17 S.-i. Kawano, N. Fujita and S. Shinkai, J. Am. Chem. Soc., 2004, 126, 8592

18 T. Kato, Science, 2002, 295, 2414.

19 A twisted nematic (TN) display is a common type of liquid-crystal display (LCD) that consists of a nematic liquid crystal confined between two plates of vertically aligned polarized glass.

20 N. Mizoshita, K. Hanabusa and T. Kato, Adv. Mater., 1999, 11, 5.

21 N. Mizoshita, Y. Suzuki, K. Kishimoto, K. Hanabusa and T. Kato, J. Mater. Chem., 2002, 12, 2197.

22 N. Mizoshita, T. Kutsuna, K. Hanabusa and T. Kato, Chem. Commun., 1999, 781.

23 M. Moriyama, N. Mizoshita, T. Yokota, K. Kishimoto and T. Kato, Adv. Mater., 2003, 15, 1335.

24 K. Hanabusa, K. Hiratsuka, M. Kimura and H. Shirai, Chem. Mater., 1999, 11, 649.

25 F. Placin, J.-P. Desvergne and J.-C. Lassègues, Chem. Mater., 2001, 13, 117.

26 W. Kubo, T. Kitamura, K. Hanabusa, Y. Wada and S. Yanagida, Chem. Commun., 2002, 374.

27 N. Mohmeyer, P. Wang, H.-W. Schmidt, S. M. Zakeeruddin and M. Grätzel, J. Mater. Chem., 2004, 14, 1905.

28 A. Ajayaghosh, S. J. George and V. K. Praveen, Angew. Chem. Int. Ed., 2003, 42, 332.

29 K. Sugiyasu, N. Fujita and S. Shinkai, Angew. Chem. Int. Ed., 2004, 43, 1229.

30 T. Nakashima and N. Kimizuka, Adv. Mater., 2002, 14, 1113.

31 K. J. C. van Bommel, A. Friggeri and S. Shinkai, Angew. Chem. Int. Ed., 2003, 42, 980.

32 K. Yoza, Y. Ono, K. Yoshihara, T. Akao, H. Shinmori, M. Takeuchi, S. Shinkai and D. Reinhoudt, Chem. Commun., 1998, 907.

33 J. H. Jung, Y. Ono, K. Hanabusa and S. Shinkai, J. Am Chem. Soc., 2000, 122, 5008.
34 K. Sugiyasu, S.-i. Tamaru, M. Takeuchi, D. Berthier, I. Huc, R. Oda and S. Shinkai, Chem. Commun., 2002, 1212.

35 S. Kobayashi, N. Hamasaki, M. Suzuki, M. Kimura, H. Shirai and K. Hanabusa, J. Am. Chem. Soc., 2002, 124, 6550.

36 G. Gundiah, S. Mukhopadhyay, U. G. Tumkurkar, A. Govindaraj, U. Maitra and C. N. R. Rao, J. Mater. Chem., 2003, 13, 2118.

37 M. Llusar, C. Roux, J. L. Pozzo and C. Sanchez, J. Mater. Chem., 2003, 13, 442 .

38 J. J. E. Moreau, L. Vellutini, M. W. C. Man and C. Bied, J. Am. Chem. Soc., 2001, 123, 1509.

39 U. Beginn, S. Keinath and M. Möller, Macromol. Chem. Phys., 1998, 199, 2379.

40 W. Gu, L. Lu, G. B. Chapman and R. G. Weiss, Chem. Commun., 1997, 543.

41 R. J. H. Hafkamp, B. P. A. Kokke, I. M. Danke, H. P. M. Geurts, A. E. Rowan, M. C. Feiters and R. J. M. Nolte, Chem. Commun., 1997, 545.

42 M. de Loos, J. van Esch, I. Stokroos, R. M. Kellogg and B. L. Feringa, J. Am Chem. Soc., 1997, 119, 12675.

43 C. Li, T. Hatano, M. Takeuchi and S. Shinkai, Chem. Commun., $2004,2350$.

44 A. M. Shipway, E. Katz and I. Willner, ChemPhysChem., 2000, 1, 18.

45 B. Simmons, S. Li, V. T. John, G. L. McPherson, C. Taylor, D. K. Schwartz and K. Maskos, Nanoletters, 2002, 2, 1037.

46 M. Kimura, S. Kobayashi, T. Kuroda, K. Hanabusa and H. Shirai, Adv. Mater., 2004, 16, 335.

47 (a) J.-T. Simonnet and S. Legret, 2000, Eur. Pat. Appl., EP 106300; (b) J.-T. Simonnet and S. Legret, 2001, Eur. Pat. Appl., EP 1082956.

48 Y. K. Ghosh and S. Bhattacharya, Chem. Commun., 2001, 185.

49 D. R. Trivedi, A. Ballabh and P. Dastidar, Chem. Mater., 2003, 15, 3971.

50 K. Y. Lee and D. J. Mooney, Chem. Rev., 2001, 101, 1869.

51 S. Murdan, G. Gregoriadis and A. T. Florence, Eur. J. Pharm. Sci., 1999, 8, 177.

52 A. Friggeri, B. L. Feringa and J. van Esch, J. Controlled Release, 2004, 97, 241

53 B. Xing, C.-W. Yu, K.-H. Chow, P.-L. Ho, D. Fu and B. Xu, J. Am. Chem. Soc., 2002, 124, 14846.

54 R. I. Petrova and J. A. Swift, J. Am. Chem. Soc., 2004, 126, 1168 and references therein.

55 S. Kiyonaka, K. Sada, I. Yoshimura, S. Shinkai, N. Kato and I. Hamachi, Nature Mater., 2004, 3, 58.

56 I. Yoshimura, Y. Miyahara, N. Kasagi, H. Yamane, A. Ojida and I. Hamachi, J. Am. Chem. Soc., 2004, 126, 12204. 